NBER WORKING PAPER SERIES

\title{
GRADUAL PORTFOLIO ADJUSTMENT: \\ IMPLICATIONS FOR GLOBAL EQUITY PORTFOLIOS AND RETURNS
}

\author{
Philippe Bacchetta \\ Eric van Wincoop \\ Working Paper 23363 \\ http://www.nber.org/papers/w23363 \\ NATIONAL BUREAU OF ECONOMIC RESEARCH \\ 1050 Massachusetts Avenue \\ Cambridge, MA 02138 \\ April 2017
}

Eric van Wincoop gratefully acknowledges financial support from the Bankard Fund for Political Economy and the Hong Kong Institute for Monetary Research. Philippe Bacchetta thanks the Swiss National Science Foundation. We thank Jessica Leutert and Fang Liu for research assistance and seminar participants at the University of Lausanne for useful comments. The views expressed herein are those of the authors and do not necessarily reflect the views of the National Bureau of Economic Research.

NBER working papers are circulated for discussion and comment purposes. They have not been peer-reviewed or been subject to the review by the NBER Board of Directors that accompanies official NBER publications.

(C) 2017 by Philippe Bacchetta and Eric van Wincoop. All rights reserved. Short sections of text, not to exceed two paragraphs, may be quoted without explicit permission provided that full credit, including $\odot$ notice, is given to the source. 
Gradual Portfolio Adjustment: Implications for Global Equity Portfolios and Returns Philippe Bacchetta and Eric van Wincoop

NBER Working Paper No. 23363

April 2017

JEL No. F30,F41,G11,G12

\begin{abstract}
$\underline{\text { ABSTRACT }}$
Modern open economy macro models assume the continuous adjustment of international portfolio allocation. We introduce gradual portfolio adjustment into a global equity market model. Our approach differs from related literature in two key dimensions. First, the time interval between portfolio decisions is stochastic rather than fixed, leading to a smoother response to shocks. Second, rather than only considering asset returns, we also use data on portfolio shares to confront the model to the data. Conditional on reasonable risk aversion, we find that the data is consistent with infrequent portfolio decisions, with a frequency of at most once in 15 months on average.

Philippe Bacchetta

Faculty of Business and Economics

University of Lausanne

Intranef 523

CH-1015 Lausanne

Switzerland

philippe.bacchetta@unil.ch

Eric van Wincoop

Department of Economics

University of Virginia

P.O. Box 400182

Charlottesville, VA 22904-4182

and NBER

vanwincoop@virginia.edu
\end{abstract}

A technical appendix is available at http://www.nber.org/data-appendix/w23363 


\section{Introduction}

Expected return differentials have been at the center of open economy macro models at least since Mundell-Fleming, where cross-border capital flows are driven by interest rate differentials. There is a variety of evidence that return differentials play a critical role in global capital flows. A well-known example is the "carry trade" that is based on interest differentials 1 The Mundell-Fleming model was succeeded by portfolio balance models, where portfolios (stocks) rather than flows depend on return differentials. Modern open economy macro models are more micro founded but share the feature of portfolio balance models in that it is portfolios rather than changes in portfolios (portfolio flows) that depend on return differentials. This has several implications. The immediate response of portfolios of all investors to any return differential implies that in equilibrium return differentials are often very small $:^{2}$ Moreover, financial shocks, such as portfolio shifts resulting from changes in risk, risk-aversion, liquidity trade, hedging or FX intervention, have little effect on capital flows and asset prices. Due to the sensitivity of portfolios to expected returns in these models, a portfolio shift towards a country's assets causes a very small (third-order) drop in its expected excess return that reverses the flows and generates equilibrium ${ }^{3}$

It is difficult to reconcile the behavior of international portfolio positions and asset prices with these modern open economy models. First, expected return differentials are not zero or close to zero. The forward discount puzzle is probably the best known example of this. Second, there is suggestive evidence of gradual international portfolio adjustment in the form of autocorrelated portfolio flows and

\footnotetext{
${ }^{1}$ Another well-documented example is capital flows to emerging markets associated with changes in interest rates in creditor countries. See for example Calvo et al. (1996). Bruno and Shin (2015) document the effect of interest rates on international banking flows. Didier and Lowenkron (2012) show that net capital flows associated with expected returns in a model with portfolio choice are significantly correlated with actual net capital flows.

${ }^{2}$ In some cases uncovered interest rate parity is assumed outright or follows from linearization methods. Many models though do not adopt such approximations and put portfolio choice at the center. Examples are Devereux and Sutherland (2007, 2010), Didier and Lowenkron (2012), Evans and Hnatkovska (2014), Hnatkovska (2010), Kraay and Ventura (2000) and Tille and van Wincoop (2010, 2014).

${ }^{3}$ Tille and van Wincoop (2014) show that first-order changes in portfolio shares are associated with third-order changes in expected returns. This is because expected returns are divided by second order moments (e.g. the variance of the excess return) in optimal portfolios.
} 
a positive linkage of flows with lagged returns (e.g., see Bohn and Tesar (1996), Calderon et al. (2003) and Froot et al. (2001)) 4 Third, financial shocks such as those listed above do affect capital flows and asset prices. Gourio et al. (2014) show that time-varying risk affects capital flows. Blanchard et al. (2016) provide evidence that large foreign exchange intervention has a significant effect on exchange rates $5^{5}$ Warnock and Warnock (2009) document the significant effect of capital inflows on U.S. interest rates.

Gabaix and Maggiori (2015) have brought expected return differentials back to the forefront in a model where all financial flows are intermediated by global financiers with limited risk-bearing capacity. This has the same effect as making agents more risk-averse, which weakens the portfolio response to changes in expected returns. Larger expected return differentials are then needed to generate equilibrium in asset markets. Gabaix and Maggiori (2015) show that such a model implies predictable deviations from uncovered interest rate parity and a significant impact of exogenous portfolio flows and FX intervention on exchange rates and the macro economy in general.

In this paper we take a different route, which aligns more closely with the original Mundell-Fleming model. We consider the role of gradual portfolio adjustment to changes in expected returns in the context of a two-country model. Like high risk aversion, it weakens the immediate portfolio response to shocks and gives rise to larger equilibrium expected return differentials as markets are thinner. There is well-known evidence of infrequent portfolio adjustment by households 6 It is also consistent with some of the open economy evidence on portfolio flows and returns mentioned above. But to date no systematic analysis of gradual portfolio adjustment in an open economy context has been conducted.

\footnotetext{
${ }^{4}$ Bohn and Tesar (1996) conclude "we suspect that investors may adjust their portfolios to new information gradually over time, resulting in both autocorrelated net purchases and a positive linkage with lagged returns. A full explanation for U.S. international investment behavior must account for the slow adjustment in the foreign portfolio over time, as well as the bias toward domestic equity."

${ }^{5}$ See also the discussion in Gabaix and Maggiori (2015), who argue that the recent large FX interventions in Switzerland and Israel have been effective and that evidence of a weaker impact of FX intervention in the earlier literature is due to the small size of the interventions.

${ }^{6}$ See for example Ameriks and Zeldes (2004), Bilias et al. (2010), Brunnermeier and Nagel (2008) and Mitchell et al. (2006). See Duffie (2010) for a broad range of evidence motivating models of infrequent portfolio adjustment.
} 
Our approach differs from the related literature on infrequent portfolio adjustment in two key respects.7 First, we use both international portfolio and asset return data to evaluate a model with gradual portfolio adjustment. Second, we model the gradual portfolio adjustment in the form of a probability of changing the portfolio rather than staggered adjustment at fixed intervals.

The literature on infrequent portfolio adjustment often does not explicitly estimate or calibrate models to confront to data. Papers that do focus mostly on asset prices. Examples are Bacchetta and van Wincoop (2010), Bougasslovsky (2016), Chien et al. (2012) and Hendershott et al. (2013). Bacchetta and van Wincoop (2010) study the forward discount puzzle (predictability of exchange rates by interest differentials). Bogousslavsky (2015) considers predictability patterns in the time-series and cross-section of stock returns. Chien et al. (2012) focus on the counter-cyclicality of the Sharpe ratio. Hendershott et al. (2013) consider stock price behavior and analyze deviations from efficient prices 8 To date asset prices and portfolios have not been used jointly to evaluate models of gradual portfolio adjustment.

Analysis of international portfolio data has been made possible by the development of a data set by Bertaut and Tryon (2007) and Bertaut and Judson (2014) of monthly bilateral equity claims and liabilities of the United States. Together with stock market capitalization data it allows us to compute the portfolio share of US investors in the rest of the world and the portfolio share of the rest of the world in the US. The portfolio data is consistent with the U.S. Treasury annual benchmark surveys. The data are considered to be of good quality and have recently been used by Curcuru et al. (2008, 2010) and Curcuru et al. (2011) to analyze return differentials and the relationship between portfolio reallocations and past returns.

The second difference with respect to related literature on infrequent portfolio adjustment is in the way we model such behavior. We assume that investors have a probability $p$ of adjusting their portfolio each period. The assumption of a Poisson distribution has been used in numerous contexts, such as Blanchard-

\footnotetext{
${ }^{7}$ For recent contributions, see Abel et. al (2007), Bogousslavsky (2016), Chien et al. (2012), Duffie (2010), Greenwood et al. (2015), Hendershott et al. (2013), Mitchell et al. (2007) and Vayanos and Woolley (2012). Earlier papers examine the impact of infrequent portfolio adjustments taking the process of asset returns as exogenous, e.g. see Lynch (1996) or Gabaix and Laibson (2002).

${ }^{8}$ Hendershott et al. (2013) also consider the implications of their model for the equity trading volume and individual's net trades.
} 
Yaari perpetual youth models or Calvo price-setting models, but is new to the literature on portfolio adjustment. The standard assumption is that agents adjust their portfolios in a staggered way every $T$ periods. In empirical applications this has the drawback that it generates a significant discontinuity in the impulse response to shocks that happens $T$ periods after the shock. This occurs because the initial group of infrequent traders who change their portfolio at the time of the shock will change their portfolio again $T$ periods later, with predictable certainty. The anticipation of this by other traders significantly affects the equilibrium. The constant probability setup that we adopt here implies more smoothness as the agents who change their portfolio at the time of a shock will change their portfolio again at varying dates in the future.

We show that this framework generates intuitive portfolios. Optimal portfolio shares depend on expected future excess returns, with the weight on future expected returns declining at the rate $\beta(1-p)$, where $\beta$ is the time discount rate. Less frequent portfolio changes (lower $p$ ) therefore imply a longer investment horizon that gives more weight to expected returns further into the future. Portfolio shares are then less sensitive to short term expected excess returns. At any time a fraction $1-p$ of the agents does not change their portfolio at all and those that do have a longer horizon and therefore respond less to short term expected returns.

The model that we develop focuses on the global equity market. There are two types of investors: frequent traders who change their portfolio each period and infrequent traders who change their portfolio each period with a probability $p$. We focus on relative equity prices, which affect the excess return, and on the average portfolio share allocated to US equity. The model is driven by three types of shocks: dividend shocks, wealth/supply shocks and financial shocks. The latter are exogenous portfolio shifts that are unrelated to expected returns. Some parameters are calibrated, but parameters about which we have little direct observable information are estimated. We use the Simulated Method of Moments for estimation, including 15 moments involving the excess return, average portfolio share, relative earnings and the relative wealth/supply shock.

The remainder of the paper is organized as follows. In Section 2 we develop a partial equilibrium model of portfolio choice when portfolio decisions are infrequent. In Section 3 we embed this in a general equilibrium model for the global equity market. Section 4 describes the quantitative approach. The results are presented in Section 5. Section 6 concludes. 


\section{Portfolio Choice under Infrequent Adjustment}

In this section, we present a partial equilibrium portfolio choice problem with infrequent portfolio adjustment. This will be embedded in a general equilibrium model for the equity market in the next section. To provide a better perspective about the approach that we adopt, we start by making some general remarks about modeling portfolio choice in an open economy DSGE setting with incomplete markets.

\subsection{Portfolio Choice under Incomplete Markets}

Even in the absence of infrequent portfolio adjustment, solving DSGE models with portfolio choice is not trivial. Under incomplete markets, there are three possible approaches. The first is to write down all the first order conditions and solve the model through a global solution method, like value function iteration on a discretized state space. This is not the approach that we will follow here. One drawback is that it is a bit of a black box approach in that there are no closed form solutions of portfolios as a function of expected returns, which will be key to our model. In addition, even under continuous portfolio adjustment, this approach is numerically very challenging. 9 The problem is that very small changes in state variables that imply tiny asset prices changes can induce very large portfolio shifts. The sensitivity of portfolios to expected returns emphasized in the introduction therefore also poses numerical challenges.

The second approach is the one specifically developed for open economy DSGE models with portfolio choice by Devereux and Sutherland $(2007,2010)$ and Tille and van Wincoop (2010). It extends local approximation methods to models with portfolio choice. A drawback here is that one needs to go to very high orders, at least the third-order component of equations and variables, to get at the features that we are interested in. This requires at least cubic Taylor expansions. The reason is that many shocks, including two out of the three shocks in our model, do not have a first-order effect on asset prices and portfolio shares. Third-order is generally very small in models with continuous portfolio adjustment. It could be of non-trivial size in a model with gradual portfolio adjustment, but cubic

\footnotetext{
${ }^{9}$ See for example Krusell and Smith (1997) for the difficulties of this approach in a closed economy setting with continuous portfolio adjustment.
} 
approximations of all equations significantly complicates the analysis and even more so under gradual portfolio adjustment 10

The approach that we take here involves first computing an explicit portfolio expression by substituting the log-linearized intertemporal budget constraint into the first-order conditions for optimal portfolio choice. This is similar to the method in Campbell and Viceira (2002) to solve partial equilibrium portfolio problems. This in turn is influenced by the approach developed in Campbell (1993), though portfolios are not explicit in the latter. This gives a portfolio expression in which optimal portfolio shares are linear in expected future returns, which can be combined with linearized equations for the rest of the model to solve for the equilibrium 11

When applying this approach to a framework where agents adjust their portfolios gradually, we will abstract from decisions other than portfolio choice. While preferably one would simultaneously solve for optimal portfolio allocation and optimal consumption, we will simply assume that agents consume a constant fraction $\zeta$ of their wealth each period. Solving simultaneously for optimal consumption and portfolios creates additional challenges that would deflect from our focus on gradual portfolio adjustment. One would need to combine infrequent portfolio decisions with either frequent or infrequent consumption decisions. In addition, it would be necessary to separate risk-aversion from intertemporal elasticity of substitution (Epstein-Zin). Finally, to linearize there would need to exist a deterministic steady state for wealth and consumption, which requires features such as finite lives (positive probability of death) or Uzawa preferences.

\subsection{Assumptions Regarding Infrequent Portfolio Choice}

We will assume that there are two assets, a Home asset and a Foreign asset with returns of $R_{H, t+1}$ and $R_{F, t+1}$ from time $t$ to $t+1$. Agents need to choose the

\footnotetext{
${ }^{10}$ It gets even more complicated in that the method shows that we need to combine the fourthorder component of the difference across countries in portfolio Euler equations with the thirdorder component of other equations in order to solve for the second-order component of the difference across countries in portfolio shares together with the third-order component of other variables. This requires taking a fourth-order Taylor expansion of the portfolio Euler equations, which is quite messy.

${ }^{11}$ Importantly, linear does not mean first-order as expected returns are divided by the variance of the excess return.
} 
portfolio share to allocate to these assets. Some of the agents are "infrequent traders" who make a new portfolio allocation decision with a probability $p$ each period. ${ }^{12}$ Others, the "frequent traders," choose the optimal portfolio allocation each period.

Analogous to Keynesian models with infrequent price setting by firms, one also needs to make an ancillary assumption about how agents allocate their portfolio at times when they do not make a new portfolio decision. In the case of price setting by firms, such assumptions range from holding the price constant, to holding the relative price constant (full indexation), to partial indexation, to following a price schedule until the next price setting decision. ${ }^{13}$ Analogously, for portfolio choice one could consider holding the portfolio share constant (rebalancing) until the next portfolio decision, not rebalancing by simply re-investing the returns in the two assets, partial rebalancing, or following a portfolio allocation schedule until the next portfolio decision. These are only some of the possibilities. Here we will assume that agents hold their portfolio share constant until the next portfolio decision and leave an exploration of alternatives for future work.

We should also clarify that the terminology of infrequent versus frequent traders does not refer to the frequency of trading itself, but rather to the frequency of making new portfolio allocation decisions. Since we assume a constant portfolio share between portfolio decisions, even the infrequent traders will generally trade to rebalance their portfolio.

\subsection{Wealth Accumulation}

Consider Home agent $j$, whose time $t$ portfolio share allocated to the Home asset is denoted $z_{H t}^{j}$. The agent earns a portfolio return of

$$
R_{t+1}^{p H j}=z_{H t}^{j} R_{H, t+1}+\left(1-z_{H t}^{j}\right) R_{F, t+1} e^{-\tau_{H t}}
$$

\footnotetext{
${ }^{12}$ The basic motive behind infrequent trading is the presence of information processing costs, that we do not model explicitly. Abel et al. (2013) propose microfoundations for infrequent portfolio decisions and show that time-dependent decisions are optimal when fixed transactions costs are small. In our model, transactions costs are zero.

${ }^{13}$ In Mankiw and Reis (2002), firms adjust their pricing plans infrequently due to random arrival of information. This implies a gradual response to shocks as in our framework. On the other hand, firms' prices may change every period.
} 
We introduce a fee $\tau_{H t}$ on the Foreign return. This is a commonly adopted feature to introduce portfolio home bias. 14

Allowing $\tau_{H t}$ to be time varying generates exogenous portfolio shifts, which we will refer to as financial shocks. Per unit of wealth invested, the fee is $T_{H, t+1}=$ $\left(1-z_{H t}^{j}\right) R_{F, t+1}\left(1-e^{-\tau_{H t}}\right)$. We assume that the fee is paid to a broker, but returned to investors. Per unit of wealth invested, the agent therefore receives a return of

$$
\hat{R}_{t+1}^{p H j}=R_{t+1}^{p H j}+T_{H, t+1}=z_{H t}^{j} R_{H, t+1}+\left(1-z_{H t}^{j}\right) R_{F, t+1}
$$

as if the fee did not exist. But from the perspective of portfolio choice we assume that the investor takes the credit $T_{H, t+1}$ as given, not under its control, for example because it is based on an average of agents with the same portfolio. The fee therefore affects the optimal portfolio, but not wealth accumulation. We assume that the fee $\tau_{H t}$ applies to all Home investors that make a new portfolio decision at time $t$ and remains the same until agents choose a new portfolio.

Financial wealth changes because of portfolio returns, non-asset income and consumption. Denote the wealth of this agent in period $t$ as $W_{H t}^{j}$. This is after portfolio returns and non-asset income, but before consumption. As discussed above, we assume that agents consume a fraction $\zeta$ of their wealth each period. The agent then invests $(1-\zeta) W_{H t}^{j}$ at the end of period $t$ and wealth accumulates according to

$$
W_{H, t+1}^{j}=(1-\zeta)\left(R_{t+1}^{p H j}+T_{H, t+1}\right) W_{H t}^{j}+G_{H, t+1}
$$

where $G_{H, t+1}$ is non-asset income, which is the same for all Home agents and follows a given stochastic process.

Analogously, for a Foreign agent $j$ we have

$$
\begin{aligned}
& R_{t+1}^{p F j}=z_{F t}^{j} R_{H, t+1} e^{-\tau_{F t}}+\left(1-z_{F t}^{j}\right) R_{F, t+1} \\
& W_{F, t+1}^{j}=(1-\zeta)\left(R_{t+1}^{p F j}+T_{F, t+1}\right) W_{F t}^{j}+G_{F, t+1}
\end{aligned}
$$

The portfolio share $z_{F t}^{j}$ refers to the share by the Foreign agent $j$ allocated to the Home asset and $T_{F, t+1}$ is the reimbursement of the fee per unit of wealth, such that $R_{t+1}^{p F j}+T_{F, t+1}=z_{F t}^{j} R_{H, t+1}+\left(1-z_{F t}^{j}\right) R_{F, t+1}$.

\footnotetext{
${ }^{14}$ Examples are Tille and van Wincoop (2010, 2014), Coeurdacier (2009), Coeurdacier et.al. (2014) and Martin and Rey (2004).
} 


\subsection{Optimal Portfolio Infrequent Traders}

We will now consider the optimal portfolio choice of a Home agent $j$ who makes a new portfolio decision at time $t$. The agent is an infrequent trader and therefore takes into account that the portfolio share $z_{H t}^{j}$ will remain constant until the next time a portfolio decision is made. To save notation, we will omit the $j$ superscript as the portfolio problem will be identical for all Home infrequent traders choosing a new portfolio. We will add a tilde to indicate that it is a new portfolio, so $z_{H t}^{j}=\tilde{z}_{H t}$ for all Home infrequent traders that choose a new portfolio at time $t$.

The agent chooses her portfolio to maximize

$$
\sum_{s=1}^{\infty} \beta^{s} E_{t} \frac{C_{H, t+s}^{1-\gamma}}{1-\gamma}
$$

where $C_{H t}$ is consumption of the Home agent at time $t$. Since agents consume a constant fraction of wealth, $C_{H, t+s}=\zeta W_{H, t+s}$. The agent therefore maximizes

$$
\sum_{s=1}^{\infty} \beta^{s} E_{t} \frac{W_{H, t+s}^{1-\gamma}}{1-\gamma}
$$

subject to (5).

The agent faces uncertainty about future portfolio returns, non-asset income, and the time of the next portfolio decision. The probability that the agent chooses the next portfolio at time $t+i$ is $p_{i}=p(1-p)^{i-1}$. We can then write

$$
E_{t} W_{H, t+s}^{1-\gamma}=\sum_{i=1}^{s-1} p_{i} E_{t} W_{H, t+s}(i)^{1-\gamma}+\left(1-\sum_{m=1}^{s-1} p_{m}\right) E_{t} \hat{W}_{H, t+s}^{1-\gamma}
$$

Here the expectations on the right hand side only depend on portfolio returns and non-asset income. $W_{H, t+s}(i)$ denotes wealth at $t+s$ conditional on the next portfolio change taking place at $t+i<t+s$. This means that the portfolio share $\tilde{z}_{H t}$ is held constant until $t+i$. $\hat{W}_{H, t+s}$ denotes wealth at $t+s$ conditional on the next portfolio change taking place at $t+s$ or later. In that case the portfolio share $\tilde{z}_{H t}$ remains constant until at least $t+s$.

The first-order condition for the optimal portfolio $\tilde{z}_{H t}$ is then

$$
\begin{aligned}
& \sum_{s=1}^{\infty} \sum_{i=1}^{s-1} p_{i} \beta^{s} E_{t} W_{H, t+s}(i)^{-\gamma} \frac{\partial W_{H, t+s}(i)}{\partial \tilde{z}_{H t}}+ \\
& \sum_{s=1}^{\infty}\left(1-\sum_{m=1}^{s-1} p_{m}\right) \beta^{s} E_{t} \hat{W}_{H, t+s}^{-\gamma} \frac{\partial \hat{W}_{H, t+s}}{\partial \tilde{z}_{H t}}=0
\end{aligned}
$$


We have

$$
\frac{\partial W_{H, t+s}(i)}{\partial \tilde{z}_{H t}}=\frac{\partial W_{H, t+i}}{\partial \tilde{z}_{H t}} \frac{\partial W_{H, t+s}}{\partial W_{H, t+i}}
$$

where

$$
\begin{aligned}
& \frac{\partial W_{H, t+s}}{\partial W_{H, t+i}}=(1-\zeta)^{s-i} \hat{R}_{t+i, t+s}^{p H} \\
& \frac{\partial W_{H, t+i}}{\partial \tilde{z}_{H t}}=\sum_{j=1}^{i}(1-\zeta)^{i-j+1}\left(R_{H, t+j}-R_{F, t+j} e^{-\tau_{H t}}\right) \hat{R}_{t+j, t+i}^{p H} W_{H, t+j-1}
\end{aligned}
$$

Here $\hat{R}_{t+i, t+s}^{p H}=\prod_{j=i+1}^{s} \hat{R}_{t+j}^{p H}$ is the cumulative portfolio return from $t+i$ to $t+s$. $\partial \hat{W}_{H, t+s} / \partial \tilde{z}_{H t}$ is equal to $\partial W_{H, t+i} / \partial \tilde{z}_{H t}$ for $i=s$.

The next steps are similar to Campbell (1993) and involve a significant amount of algebra that we leave for the Technical Appendix. After substituting the expressions in the last three equations into the first-order condition (9), we write the first order condition in terms of expectations of the exponential of terms involving log portfolio returns and log wealth at future dates. We then substitute expressions for log-linearized portfolio returns and wealth. Assuming normality of log returns, we then compute the expectation. We finally linearize the resulting exponential expression. In what follows the excess return is equal to

$$
e r_{t+1}=r_{H, t+1}-r_{F, t+1}
$$

where $r_{H, t+1}$ is the $\log$ of the Home return $R_{H, t+1}$ and $r_{F, t+1}$ is the log Foreign return.

Leaving the algebraic details to the Technical Appendix, we obtain the following optimal portfolio $\tilde{z}_{H t}$ :

$$
\tilde{z}_{H t}=0.5+\frac{1}{D} \sum_{s=1}^{\infty}[\beta(1-p)]^{s-1} E_{t} e r_{t+s}+h_{H t}^{i}
$$

where

$$
D=\sum_{s=1}^{\infty}[\beta(1-p)]^{s-1}\left[\tilde{\gamma} \operatorname{var}_{t}\left(e r_{t+s}\right)+2(\tilde{\gamma}-1) \sum_{i<s} \theta^{s-i} \operatorname{cov}_{t}\left(e r_{t+s}, e r_{t+i}\right)\right]
$$

and

$$
\tilde{\gamma}=\theta \frac{1-\beta \theta}{1-\beta \theta^{2}} \gamma
$$

and $\theta=(1-\zeta) \bar{R}<1$, with $\bar{R}$ the steady state of asset returns. 
The optimal portfolio has two components. The first and most important part depends on future expected excess returns. A lower $p$ implies less frequent portfolio decisions are therefore a longer effective horizon. The expected length of time until the next portfolio decision is $1 / p$. The optimal portfolio depends on expectations of all future excess returns, with the weight declining at the rate $\beta(1-p)$. A lower value of $p$ therefore leads to a higher weight on expected excess returns further into the future. As usual with optimal portfolios, the response to changes in expected returns is lower the higher the rate of risk aversion and the higher the risk associated with future excess returns. This is captured by the denominator $D$ of the optimal portfolio. The adjusted risk-aversion parameter $\tilde{\gamma}$ differs from $\gamma$ as a result of non-asset income.

The second part of the optimal portfolio is $h_{H t}^{i}$. This is the part of the portfolio that does not depend on expectations of future excess returns. The full expression for $h_{H t}^{i}$ is lengthy and reported in Appendix B. It is made up of three types of terms, capturing a hedge against future non-asset income $G_{H, t+1}$, a hedge against changes in future portfolio returns (changing investment opportunity set) and the cost $\tau_{H t}$ of investing abroad. We will refer to this as the hedge term of the portfolio, even though the part involving $\tau_{H t}$ is not technically a hedge. The optimal portfolio of Foreign infrequent traders $\tilde{z}_{F t}$ is the same, except for a different hedge term $h_{F t}^{i} \cdot 15$

There is a close analogy between this optimal portfolio of infrequent traders and the optimal price under Calvo price setting. The latter assumes that there is a probability $p$ of firms setting a new price each period. The expression for the optimal price (e.g. page 45 of Gali (2008)) depends on a weighted average of future marginal costs, with the weight declining at the same rate $\beta(1-p)$ as in the optimal portfolio expression (14). In the portfolio expression, the expected marginal cost at future dates is replaced by expected excess returns, scaled by $D$, and the markup is replaced by the hedge term.

This way of modeling infrequent traders is new to the literature. It is usually assumed that infrequent traders make a new portfolio decision every $T$ periods 16 In that case the optimal portfolio of infrequent traders that make a new portfolio

\footnotetext{
${ }^{15}$ To make expected returns different for Home and Foreign investors, we would have to introduce information asymmetries, as in Albuquerque et al (2007, 2009), Brennan and Cao (1997) and Tille and van Wincoop (2014). We abstract from that here.

${ }^{16}$ See for example Duffie (2010), Bacchetta and van Wincoop (2010), Lynch (1996) and Gabaix an Laibson (2001) and other references listed in footnote 5.
} 
decision depends on the expected excess return over the next $T$ periods. Drawing again on the analogy to price setting, this is like Taylor price setting, where firms choose a new optimal price every $T$ periods. We initially experimented with a similar framework here. But it has an important drawback in quantitative implementation. There is a significant discontinuity in the impulse response to shocks that happens $T$ periods after the shock. This occurs because the initial group of infrequent traders that change their portfolio at the time of the shock will change their portfolio again $T$ periods later, with predictable certainty. Other traders know this, which significantly affects their behavior as well. The Calvo-type setup that we adopt here implies more smoothness as the agents that change their portfolio at the time of a shock will change their portfolio again at varying dates in the future.

\subsection{Frequent Traders}

For frequent traders the optimal portfolio can be obtained by letting $p \rightarrow 1$, which gives

$$
z_{H t}^{f}=0.5+\frac{E_{t} e r_{t+1}}{\tilde{\gamma} \operatorname{var}_{t}\left(e r_{t+1}\right)}+h_{H t}^{f}
$$

The portfolio share chosen by the frequent traders only depends on the expected excess return over the next period. The hedge term $h_{H t}^{f}$ again captures terms unrelated to the expected excess return. The optimal portfolio share $z_{F t}^{f}$ for Foreign frequent traders is the same, again with a different hedge term $h_{F t}^{f}$.

\subsection{Average Portfolio Share}

When integrating this model of portfolio choice into a general equilibrium model in the next section, the average portfolio share allocated to the Home asset will be a key variable. Define $z_{H t}$ and $z_{F t}$ as the average portfolio share allocated to the Home asset by respectively Home and Foreign agents and $z_{t}^{A}=0.5\left(z_{H t}+z_{F t}\right)$ as the average across all agents.

We assume that a fraction $f$ of agents are frequent traders, so that

$$
z_{H t}=f z_{H t}^{f}+(1-f) z_{H t}^{i n}
$$

where the average portfolio share of the infrequent traders evolves according to

$$
z_{H t}^{i n}=(1-p) z_{H, t-1}^{i n}+p \tilde{z}_{H t}
$$


Analogously, for the Foreign country

$$
\begin{aligned}
& z_{F t}=f z_{F t}^{f}+(1-f) z_{F t}^{i n} \\
& z_{F t}^{i n}=(1-p) z_{F, t-1}^{i n}+p \tilde{z}_{F t}
\end{aligned}
$$

Putting all results of this section together, we obtain the following expression for the average portfolio share $z_{t}^{A}$ :

$$
z_{t}^{A}=0.5+f \frac{E_{t} e r_{t+1}}{\tilde{\gamma} v a r_{t}\left(e r_{t+1}\right)}+(1-f) z_{t}+n_{t}
$$

where

$$
z_{t} \equiv(1-p) z_{t-1}+\frac{p}{D} \sum_{s=1}^{\infty}[\beta(1-p)]^{s-1} E_{t} e r_{t+s}
$$

and

$$
n_{t} \equiv f h_{t}^{A, f}+(1-f) \sum_{i=0}^{\infty}(1-p)^{i} p h_{t-i}^{A, i n}
$$

Here $z_{t}$ is the component of the average portfolio share of infrequent traders that is associated with expected returns and $h_{t}^{A, f}$ and $h_{t}^{A, i n}$ are the average of the Home and Foreign hedge terms of respectively frequent and infrequent traders.

The average hedge terms, derived in the Technical Appendix and discussed in Appendix B, are

$$
\begin{aligned}
h_{t}^{A, i n} & =\frac{0.5}{D(1-\beta(1-p))} \tau_{t}^{D} \\
h_{t}^{A, f} & =\frac{0.5}{\tilde{\gamma} \operatorname{var}_{t}\left(e r_{t+1}\right)} \tau_{t}^{D}
\end{aligned}
$$

where $\tau_{t}^{D}=\tau_{H t}-\tau_{F t}$. An increase in $\tau_{t}^{D}$ implies a relative portfolio shift from the Foreign asset to the Home asset. We interpret $n_{t}$ as exogenous portfolio shifts and its innovations as financial shocks. While we have modeled them here through $\tau_{t}^{D}$, this was mainly a matter of convenience. We interpret these portfolio shifts more broadly as resulting from such factors as time varying risk, noise trade (expectational errors), liquidity trade, time varying risk-aversion, time-varying risk-bearing capacity (Gabaix and Maggiori (2015)) or changes in other investment opportunities. 


\subsection{Impact of Infrequent Portfolio Choice}

Equation (22) captures the key features of our model of gradual portfolio adjustment. It impacts the way the average portfolio share depends on expected future returns. There are at least four interrelated ways that gradual portfolio adjustment $(f<1)$ leads to a fundamentally different response to expected excess returns than in a model where all agents choose an optimal portfolio at all times $(f=1)$.

First, infrequent traders who change their portfolio have a longer horizon than frequent traders and therefore base their portfolio decision on expected returns much further into the future: $z_{t}$ depends on $\sum_{s=1}^{\infty}[\beta(1-p)]^{s-1} E_{t} e r_{t+s}$ rather than on $E_{t} e r_{t+1}$. Second, and related to the first point, infrequent traders are much less responsive to expected excess returns in the near future than frequent traders. This is because the denominator $D$ of the portfolio of infrequent traders is much larger than that of frequent traders. Third, only a fraction $p$ of infrequent traders make a portfolio decision at any point in time. This further weakens the portfolio response to changes in expected returns. This can be seen in the expression for $z_{t}$, where the expected portfolio returns are multiplied by the fraction $p$ that make a new portfolio decision.

Finally, in addition to a weaker portfolio response to expected returns in the near future, there is also a more gradual portfolio response. As can be seen in (23), the average portfolio share of infrequent traders has significant persistence. Past portfolio decisions affect the average portfolio share of infrequent traders today. Even if expected future returns today were entirely uncorrelated with expected future returns yesterday, so that the portfolio of frequent traders is iid, $z_{t}$ would still have an autocorrelation of $1-p$.

\section{Global Equity Market Model}

We now integrate the portfolio choice framework from the previous section into a general equilibrium market of the global equity market. 


\subsection{Assets and Equilibrium}

Home and Foreign equity prices and dividends at time $t$ are $Q_{i, t}$ and $D_{i, t}$. The return on equity of country $i$ is

$$
R_{i, t+1}=\frac{D_{i, t+1}+Q_{i, t+1}}{Q_{i, t}}
$$

The asset supply $K_{i t}(i=H, F)$ evolves according to

$$
K_{i, t+1}=(1-\psi) K_{i t}+I_{i t}
$$

where $\psi$ is the rate of depreciation. We take investment $I_{i t}$ exogenous: $I_{i t}=\bar{I} e^{u_{i t}}$, where $\bar{I}$ is steady state investment and $u_{i t}$ is stochastic with mean zero.

There is a continuum of agents on the interval $[0,1]$ in both countries, including both frequent and infrequent traders. The market equilibrium conditions are

$$
\begin{aligned}
Q_{H t} K_{H t} & =\int_{0}^{1} z_{H t}^{j} W_{H t}^{j} d j+\int_{0}^{1} z_{F t}^{j} W_{F t}^{j} d j \\
Q_{F t} K_{F t} & =\int_{0}^{1}\left(1-z_{H t}^{j}\right) W_{H t}^{j} d j+\int_{0}^{1}\left(1-z_{F t}^{j}\right) W_{F t}^{j} d j
\end{aligned}
$$

\subsection{Linearization}

We log-linearize the model, which requires first computing the steady state. Denote the steady state portfolio share $z_{H t}^{j}$ of all Home agents as $\bar{z}$. It is equal to 0.5 plus the steady state of the hedge term. We can set the steady state of $\tau_{H t}$ to get any $\bar{z} .17$ By symmetry, the steady state of the portfolio share $z_{F t}^{j}$ of Foreign agents is $1-\bar{z}$. Denoting steady state variables with a bar, steady state values $\bar{Q}, \bar{R}, \bar{K}$ and $\bar{W}$ can be derived from (3), 25), (26) and (27):

$$
\begin{aligned}
& \bar{R}=1+\frac{\bar{D}}{\bar{Q}} \\
& \bar{K}=\bar{I} / \psi \\
& \bar{W}=\frac{\bar{G}}{1-(1-\zeta) \bar{R}} \\
& \bar{Q} \bar{K}=\bar{W}
\end{aligned}
$$

where $\bar{I}, \bar{D}$ and $\bar{G}$ are given.

\footnotetext{
${ }^{17} \mathrm{~A}$ technicality is that the steady state cost of investment abroad may have to be slightly different for frequent traders to deliver the same steady state portfolio share $\bar{z}$.
} 
We can now log-linearize the model around these steady state values. We keep the portfolio shares in levels, while for all other variables lower case letters refer to logs. Below all variables are in deviation from their steady state. Denoting $z_{H t}=$ $\int_{0}^{1} z_{H t}^{j} d j, w_{H t}=\int_{0}^{1} w_{H t}^{j} d j$ and analogous for the Foreign country, the (aggregated) wealth accumulation and market clearing conditions become

$$
\begin{aligned}
& w_{H, t+1}=\theta w_{H t}+\theta\left(\bar{z} r_{H, t+1}+(1-\bar{z}) r_{F, t+1}\right)+(1-\theta) g_{H, t+1} \\
& w_{F, t+1}=\theta w_{F t}+\theta\left((1-\bar{z}) r_{H, t+1}+\bar{z} r_{F, t+1}\right)+(1-\theta) g_{F, t+1} \\
& k_{H t}+q_{H t}=z_{H t}+z_{F t}+\bar{z} w_{H t}+(1-\bar{z}) w_{F t} \\
& k_{F t}+q_{F t}=-z_{H t}-z_{F t}+(1-\bar{z}) w_{H t}+\bar{z} w_{F t}
\end{aligned}
$$

where $\theta=(1-\zeta) \bar{R}<1.18$

We can take the sum and the difference of these equations across countries. When we take the sum, we can compute the average equity price and average wealth. Portfolio allocation does not affect these variables other than through steady state portfolios. We will focus on the difference of the equations across countries, which depends on the portfolio shares in deviation from steady state that is critical to our analysis. Denoting the difference between the Home and Foreign variables with a superscript $D$, we then have

$$
\begin{aligned}
& w_{t+1}^{D}=\theta w_{t}^{D}+\theta(2 \bar{z}-1) e r_{t+1}+(1-\theta) g_{t+1}^{D} \\
& k_{t}^{D}+q_{t}^{D}=4 z_{t}^{A}+(2 \bar{z}-1) w_{t}^{D}
\end{aligned}
$$

where $z_{t+1}^{A}=0.5\left(z_{H, t}+z_{F, t}\right)$ and an expression for the excess return $e r_{t+1}=$ $r_{H, t+1}-r_{F, t+1}$ can be derived by log-linearizing Home and Foreign returns:

$$
e r_{t+1}=(1-\delta) q_{t+1}^{D}-q_{t}^{D}+\delta d_{t+1}^{D}
$$

where $\delta=\bar{D} /(\bar{Q}+\bar{D})=(\bar{R}-1) / \bar{R}$.

Given the exogenous investment specification, we also have

$$
k_{t}^{D}=(1-\psi) k_{t-1}^{D}+\psi u_{t}^{D}
$$

In what follows we will set $\psi=1-\theta$. This simplifies the model and is a reasonable approximation ${ }^{19}$ Define $\tilde{w}_{t}^{D}=w_{t}^{D}-k_{t}^{D} /(2 \bar{z}-1)$. This combines relative wealth

\footnotetext{
${ }^{18}$ Using $\sqrt{29}-\sqrt{32}$, in steady state $\theta=[(1-\zeta) \bar{G}+(1-\zeta) \bar{D} \bar{K}] /[\bar{G}+(1-\zeta) \bar{D} \bar{K}]<1$.

${ }^{19}$ Our estimate of $\theta$ for monthly data, discussed in Section 4.2 , is 0.99 , so that $\psi=1-\theta=0.01$ implies an annual depreciation rate of $12 \%$, which accords well with the $10 \%$ that is generally used in calibration.
} 
and relative asset supply. Also define $a_{t}^{D}=(1-\theta)\left(g_{t}^{D}-u_{t}^{D} /(2 \bar{z}-1)\right)$, which combines relative wealth shocks (through non-asset income) with relative supply shocks. Then we can write the system as

$$
\begin{aligned}
& \tilde{w}_{t+1}^{D}=\theta \tilde{w}_{t}^{D}+\theta(2 \bar{z}-1) e r_{t+1}+a_{t+1}^{D} \\
& q_{t}^{D}=4 z_{t}^{A}+(2 \bar{z}-1) \tilde{w}_{t}^{D}
\end{aligned}
$$

\subsection{Shocks}

The model will be driven by three types of shocks: dividend shocks, wealth/supply shocks and financial shocks. Dividend shocks apply to relative dividends $d_{t}^{D}=$ $d_{H t}-d_{F t}$. Wealth/supply shocks apply to the variable $a_{t}^{D}$, while financial shocks apply to the exogenous portfolio shifter $n_{t}$. We assume that they all follow an $\mathrm{AR}(2)$ process:

$$
\begin{aligned}
& d_{t}^{D}=\rho_{1}^{d} d_{t-1}^{D}+\rho_{2}^{d} d_{t-2}^{D}+\varepsilon_{t}^{d} \\
& a_{t}^{D}=\rho_{1}^{a} a_{t-1}^{D}+\rho_{2}^{a} a_{t-2}^{D}+\varepsilon_{t}^{a} \\
& n_{t}=\rho_{1} n_{t-1}+\rho_{2} n_{t-2}+\varepsilon_{t}^{n}
\end{aligned}
$$

The innovations are all normally distributed with mean 0 and variance respectively $\sigma_{d}^{2}, \sigma_{a}^{2}$ and $\sigma_{n}^{2}$

\subsection{Model Summary}

It is useful to summarize the full set of equations that make up the model:

$$
\begin{aligned}
& q_{t}^{D}=4 z_{t}^{A}+(2 \bar{z}-1) \tilde{w}_{t}^{D} \\
& \tilde{w}_{t}^{D}=\theta \tilde{w}_{t-1}^{D}+\theta(2 \bar{z}-1) e r_{t}+a_{t}^{D} \\
& z_{t}^{A}=f \frac{E_{t} e r_{t+1}}{\tilde{\gamma} \operatorname{var}_{t}\left(e r_{t+1}\right)}+(1-f) z_{t}+n_{t} \\
& z_{t}=(1-p) z_{t-1}+\frac{p}{D} \sum_{s=1}^{\infty}[\beta(1-p)]^{s-1} E_{t} e r_{t+s} \\
& e r_{t+1}=(1-\delta) q_{t+1}^{D}-q_{t}^{D}+\delta d_{t+1}^{D} \\
& d_{t}^{D}=\rho_{1}^{d} d_{t-1}^{D}+\rho_{2}^{d} d_{t-2}^{D}+\varepsilon_{t}^{d} \\
& a_{t}^{D}=\rho_{1}^{a} a_{t-1}^{D}+\rho_{2}^{a} a_{t-2}^{D}+\varepsilon_{t}^{a} \\
& n_{t}=\rho_{1} n_{t-1}+\rho_{2} n_{t-2}+\varepsilon_{t}^{n}
\end{aligned}
$$

with $D$ as in 15 . 


\subsection{Solution}

Details regarding the solution can be found in the Technical Appendix. For given variances and covariances in the denominator of the portfolio expressions, we have a system of linear equations that can be solved with standard linear solution methods. We only need to truncate the infinite sum in 49 . We truncate at the horizon $T$, so that

$$
z_{t}=(1-p) z_{t-1}+\frac{p}{D} \sum_{s=1}^{T}[\beta(1-p)]^{s-1} E_{t} e r_{t+s}
$$

In practice we set $T=60$ months, so 5 years. Setting it longer does not affect the results.

While the variances and covariances that enter $D$, and in the portfolio of the frequent traders, are endogenous, we at first set all covariances in $D$ equal to 0 and set the variance of excess returns equal to $0.026^{2}$. We then solve the model. We use this model solution when estimating the parameters with the Simulated Method of Moments, discussed in Section 4.3. When we have our parameter estimates, we compute the corresponding second moments that enter the portfolio expressions. We then slightly rescale $f$ and $\tilde{\gamma}$ such that $f /\left[\tilde{\gamma} \operatorname{var}_{t}\left(e r_{t+1}\right)\right]$ and $(1-f) / D$ remain exactly the same as based on the estimated $f$ and $\tilde{\gamma}$ with the exogenously imposed second moments. The Technical Appendix discusses the details of the rescaling. By keeping these two ratios unchanged, the solution remains unchanged ${ }^{20}$ When the rescaled value of $\tilde{\gamma}$ reaches an upper bound that we have set, we simply impose that the rescaled value $\tilde{\gamma}$ must be equal to this upper bound.

We find numerically that in the case where all traders are frequent traders there is either one unique equilibrium or there are 3 equilibria. As described above, the model can be solved for a given variance of the excess return, which then maps into a new variance of the excess return implied by the solution. One can check for multiple equilibria by inspecting this mapping. Intuitively, when the variance of the excess return is low (high), portfolios respond more (less) to expected returns, leading to a smaller (larger) asset price response to financial

\footnotetext{
${ }^{20}$ As described in the Technical Appendix, one can also follow an iterative procedure for a given set of parameters. One can solve the model for given second moments, then compute the implied second moments, then solve the model for this new set of second moments, and repeat this until the second moments no longer change. This gives exactly the same results, but is far more computationally intensive.
} 
shocks to clear markets, justifying the low (high) variance.21 We do not find multiple equilibria in the estimated model with infrequent traders. The difference is that infrequent traders always have a more muted portfolio response as only a limited fraction of these agents make a new portfolio decision and they have longer horizons. Even for frequent traders though, the presence of multiple equilibria does not pose a problem as the estimation will search for the solution where the variance of the excess return is close to that in the data.

\subsection{Impulse Responses}

Before getting into the details of the data and calibration/estimation of parameters, it is useful to get a better understanding of how the model works by considering the impulse responses. Figure 1 shows impulse responses for positive dividend and wealth shocks in three cases ${ }^{22}$ These cases are based on parameter estimates that will be discussed in the next two sections. We refer to these cases as IN, FRH and FRL. Case IN, labeled infrequent traders in Figure 1, is one where almost all traders are infrequent traders $(f=0.004)$ who change their portfolio quite infrequently $(p=0.01)$ and have a risk aversion of $\tilde{\gamma}=13.9$. In cases FRL and FRH all traders are frequent traders $(f=1)$. In case FRL the rate of risk aversion is relatively low $(\tilde{\gamma}=10)$, while in case FRH the rate of risk aversion is very high $(\tilde{\gamma}=485)$.

In all cases the direction of the change in $q^{D}$ and $z^{A}$ at the time of the shock is the same. A positive dividend shock increases the expected excess return on the Home asset, which raises the average portfolio share $z^{A}$ and the relative price $q^{D}$. A positive relative Home wealth shock raises the relative demand for Home equity, which raises the relative price $q^{D}$. The higher relative price reduces the expected excess return on the Home asset, which lowers $z^{A}$. What differs across the three cases is the magnitude of the immediate response and the subsequent dynamics.

There are two key distinctions between the three cases. First, portfolios are

\footnotetext{
${ }^{21}$ McCafferty and Driskill (1980) argue that such multiple equilibria are a general feature of rational expectations models where behavior depends on a forecast variance. It also occurs in portfolio models with limited participation, such as Pagano (1989), Allen and Gale (1994) and Jeanne and Rose (2002), where a high variance leads agents to exit the market, making portfolios less responsive to prices and generating a high variance.

${ }^{22}$ We will discuss the impulse response to financial shocks in Section 5 as it is an unobserved variable for which the estimated process is different for each parameterization.
} 
Figure 1: IMPUlSE ReSPONSES*

Dividend Shocks
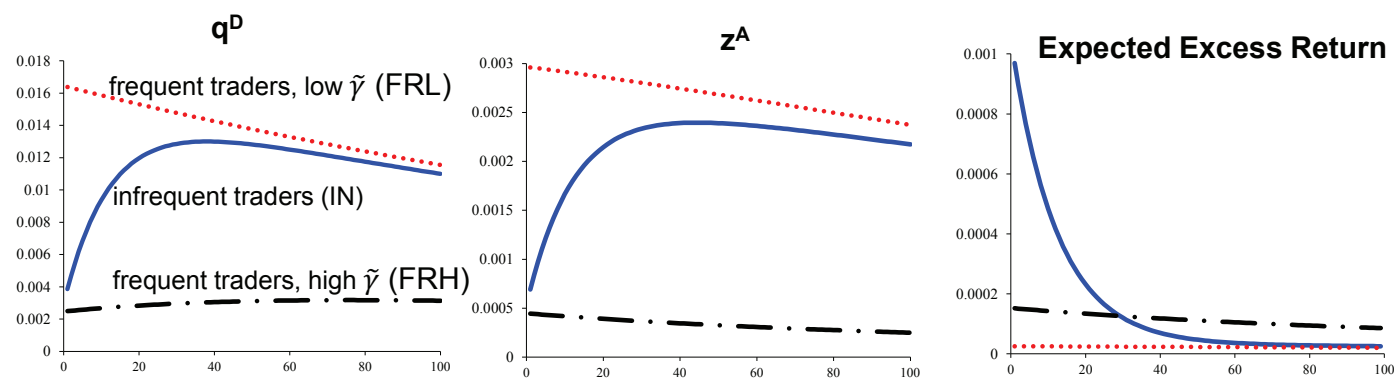

Wealth/Supply Shocks
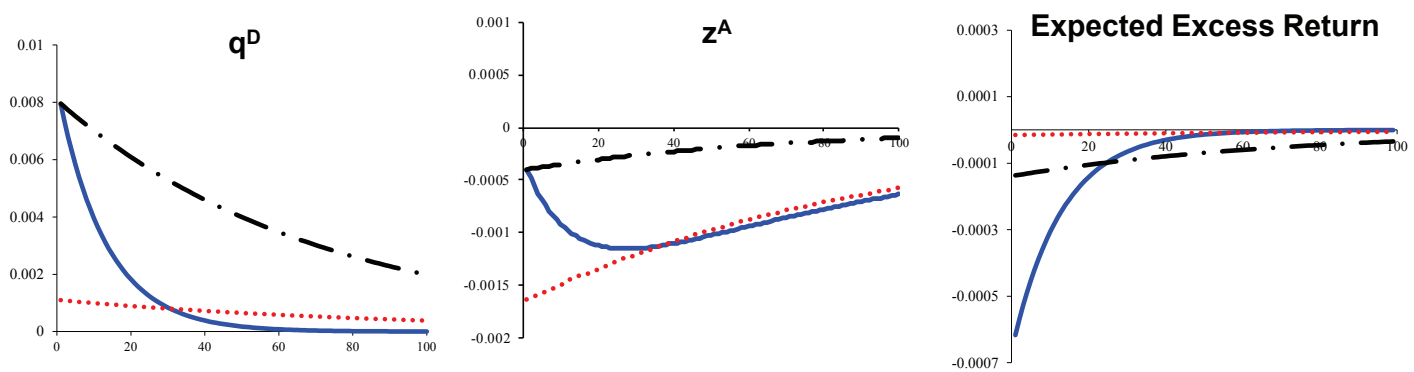

*Infrequent traders (IN): $p=0.01, f=0.004, \tilde{\gamma}=13.9$; frequent traders, low $\tilde{\gamma}(\mathrm{FRL}): f=1, \tilde{\gamma}=$ 10; frequent traders, high $\tilde{\gamma}(\mathrm{FRH}): f=1, \tilde{\gamma}=485$. Others parameters as in Tables 1-3.

much more sensitive to expected returns in the FRL case than in the FRH and IN cases. In the FRH case all agents respond right away to a change in expected returns, but they all take limited positions because of the very high risk aversion. In the IN case only a limited fraction of agents respond to a change in expected returns and even those agents have a limited response because of longer horizons. While for different reasons, both in the FRH and IN cases the immediate portfolio response will be significantly more muted than in the FRL case. The second difference is in the subsequent dynamics. In the IN case portfolios respond gradually to a shock, while in the FRL and FRH cases portfolios respond immediately and then gradually return to steady state.

These distinctions are evident in Figure 1. First consider the immediate response at the time of the shock. For both dividend and wealth shocks, $z^{A}$ changes much more in the FRL case than in the FRH and IN cases. The weaker portfolio response also translates into a much smaller change in the relative price $q^{D}$ under 
dividend shocks in the FRH and IN cases than in the FRL case. The exact opposite happens under wealth shocks. A positive relative Home wealth shock leads to an excess demand for the Home asset. In the FRL case, where portfolios are very sensitive to expected returns, a very small increase in $q^{D}$ leads to a significant portfolio response that clears the market. The weak portfolio response in the FRH and IN cases implies that the expected excess return, and therefore $q^{D}$, needs to rise much more to clear the market.

With regards to the dynamics subsequent to the shock, the response is quite different with infrequent traders (IN) than frequent traders (FRH, FRL). In the case of infrequent traders the portfolio share $z^{A}$ continues to change for quite some time in the same direction as the initial change after the shock. This is because agents gradually adjust portfolios in response to expected return changes. This happens even though expected future excess returns are slowly falling (in absolute value). By contrast, in the two cases with frequent traders the average portfolio share moves in the direction opposite to its initial change, gradually returning to its steady state due to expected excess returns that are declining in absolute value.

For dividend shocks the continued increase in the average portfolio share $z^{A}$ in the IN case also implies a continued increases in $q^{D}$ for a significant length of time. This is consistent with the phenomenon known as post earnings announcement drift, where equity prices continue to drift in the same direction as the initial change after an earnings announcement. ${ }^{23}$ By contrast, in the cases with only frequent traders the relative equity price gradually falls after the initial increase. With wealth shocks the relative price $q^{D}$ declines in all three cases subsequent to the initial increase, but much faster in the case of infrequent traders who continue to reallocate their portfolios away from the Home asset after the shock.

The chart on the right hand side shows the expected excess return, which changes much more in the case of infrequent traders than in both cases with frequent traders. The case of the dividend shock has a close analogy to the forward discount puzzle, which considers another income component of asset returns (interest differentials). As Bacchetta and van Wincoop (2010) have shown, the forward discount puzzle can be explained by gradual portfolio adjustment. A rise in the interest rate of one currency leads to a gradual portfolio shift towards that currency, which leads to continued appreciation and a positive excess return. Analogously,

\footnotetext{
${ }^{23}$ See Hong and Stein (1999) and references therein.
} 
here the higher relative Home dividend implies a gradual shift to Home equity, which continues to raise the relative price of Home equity and therefore gives rise to a high expected excess return on Home equity. This is not arbitraged away as only a small subset of agents makes new portfolio decisions and they are responsive to expected returns over longer horizons. The same phenomenon also explains the much larger change in the expected excess return under wealth shocks. This is an important way that the IN case sets itself apart from both the FRL and FRH cases.

\section{Quantitative Analysis}

We now turn to the quantitative analysis. We first discuss the data. After that we describe the calibration of a subset of parameters and the estimation of the remaining parameters with the Simulated Method of Moments. The estimation minimizes the distance between 15 data moments and corresponding model moments.

\subsection{Data}

Details regarding data construction and data sources are discussed in Appendix A. We use four series to confront the model to the data: $z_{t}^{A}, e r_{t}, d_{t}^{D}$ and $a_{t}^{D}$. The sample consists of 230 months from November 1995 to December 2014. The Home country is the US and the Foreign country is the rest of the world (ROW).

Portfolio data are obtained from Bertaut and Tryon (2007) and Bertaut and Judson (2014) ${ }^{24}$ We compute $z_{t}^{A}=\left(z_{H t}+z_{F t}\right) / 2$, where $z_{H t}=$ US external claims on ROW/(US market capitalization - US external liabilities + US external claims on ROW) and $z_{F t}=$ ROW external claims on US/(ROW market capitalization US external claims + ROW external claims on US). Market capitalization data are from MSCI ${ }^{25}$ We also compute $\bar{z}$ as the mean of the average domestic portfolio share $\left(z_{H t}+\left(1-z_{F t}\right)\right) / 2$. We find that $\bar{z}=0.7634$.

The data for $d_{t}^{D}$ and $e r_{t}$ are obtained from MSCI. Return data for the US and the aggregate of the other countries are based on the total return index. We use the

\footnotetext{
${ }^{24}$ Bertaut and Tryon (2007) and Bertaut and Judson (2014) correct TIC data to adjust for various biases. This data is used in several other studies, e.g., Curcuru et al. (2011).

${ }^{25}$ The MSCI market capitalization data is for an aggregate of 44 foreign countries, including 21 developed and 23 emerging market economies.
} 
difference in log earnings to compute $d_{t}^{D}$. We use earnings rather than dividends as dividends do not include share repurchases, which have become a preferred method of shareholder payments. One drawback of earnings is that the MSCI only provides the 12-month trailing average rather than the monthly earnings. Firms do not report monthly earnings. Moreover, even if we did have monthly or quarterly earnings, it would have a significant seasonal component and would be very volatile. Our measure is reasonable if payouts (dividends and repurchases) keep up with the 12-month trailing average of earnings. One comforting finding is that $d^{D}$ computed this way based on relative earnings has a correlation of 0.81 with the same series computed based on relative dividends, which is quite large in light of the absence of repurchases from dividends.26

Finally, from 46)-47) we have

$$
a_{t}^{D}=\frac{q_{t}^{D}-4 z_{t}^{A}-\theta\left(q_{t-1}^{D}-4 z_{t-1}^{A}\right)}{2 \bar{z}-1}-\theta(2 \bar{z}-1) e r_{t}
$$

We can therefore compute $a_{t}^{D}$ from the data on $q_{t}^{D}, z_{t}^{A}$ and $e r_{t}$. This does require an estimate of $\theta$, which we discuss below.

\subsection{Calibrated Parameters}

We estimate the parameters $p, f, \tilde{\gamma}$ and the parameters associated with the financial shock process $n_{t}$. All other parameters are calibrated and reported in Table 1. For the dividend process there are three parameters, $\rho_{1}^{d}, \rho_{2}^{d}$ and $\sigma_{d}$. It is wellknown that estimation of these parameters through a simple regression leads to small sample bias. We therefore produce 10,000 simulations of the $\mathrm{AR}(2)$ process of $d_{t}^{D}$ over 230 months and choose the parameters of the process such that the average variance and first and second-order autocovariance of $d_{t}^{D}$ match the corresponding moments in the data.

In order to compute $a^{D}$ we first need an estimate of $\theta$. For this we use an orthogonality condition based on the wealth accumulation equation (47). Since it is a bit technical, we leave a discussion of our estimate of $\theta=0.99$ to Appendix C. We find that $a^{D}$ is essentially i.i.d., with an autocorrelation of only 0.02 . We therefore set $\rho_{1}^{a}=\rho_{2}^{a}=0$ and set $\sigma_{a}$ equal to the standard deviation of $a_{t}^{D}$.

\footnotetext{
${ }^{26}$ They also have comparable standard deviations, 0.22 for relative log earnings versus 0.17 for relative $\log$ dividends.
} 
Table 1: Calibrated Parameters

\begin{tabular}{|l|l|}
\hline Parameter & Description \\
\hline$\rho_{1}^{d}=0.90706$ & autoregressive coefficient dividend process \\
$\rho_{2}^{d}=0.089257$ & autoregressive coefficient dividend process \\
$\sigma_{d}=0.045377$ & standard deviation dividend innovations \\
$\rho_{1}^{a}=0$ & autoregressive coefficient $a_{t}^{D}$ \\
$\rho_{2}^{a}=0$ & autoregressive coefficient $a_{t}^{D}$ \\
$\sigma_{a}=0.014$ & standard deviation wealth shock $\left(a_{t}^{D}\right)$ \\
$\bar{R}-1=0.01 / 3$ & steady state rate of return \\
$\beta=1 / \bar{R}=0.9967$ & time discount rate \\
$\delta=(\bar{R}-1) / \bar{R}=0.0033$ & steady state ratio of dividend/(price+dividend) \\
$\bar{z}=0.7634$ & steady state fraction invested domestically \\
$\theta=0.99$ & persistence parameter in wealth accumulation \\
\hline
\end{tabular}

We set $\bar{R}-1=0.01 / 3$, which implies an annualized return of $4 \%$. $\delta$ is equal to $(\bar{R}-1) / \bar{R}$. We set $\beta=1 / \bar{R}$. We have already discussed $\bar{z}$ above.

\subsection{Estimation}

When estimating the remaining parameters with the Simulated Method of Moments, we minimize

$$
\left(\mathbf{m}^{\text {data }}-\mathbf{m}^{\text {model }}(\nu)\right)^{\prime} \boldsymbol{\Sigma}^{-1}\left(\mathbf{m}^{\text {data }}-\mathbf{m}^{\text {model }}(\nu)\right)
$$

Here $\mathbf{m}^{\text {data }}$ is a vector of data moments and $\mathbf{m}^{\text {model }}(\nu)$ are the corresponding moments in the model as a function of the vector $\nu$ of model parameters. $\boldsymbol{\Sigma}^{-1}$ is a weighting matrix, where $\boldsymbol{\Sigma}$ corresponds to the variance of the vector of moments. The average model moments and the variance of the moments are computed based on 1000 simulations of the model over 230 months for which we have data. We adopt the common practice of only using the diagonal elements of the weighting matrix as the full matrix can lead to finite sample bias (e.g. Altonji and Segal (1996)). The objective function is therefore

$$
\sum_{i=1}^{M}\left(\frac{\mathbf{m}^{\text {data }}(i)-\mathbf{m}^{\text {model }}(i)}{\Sigma_{\mathbf{i i}}^{\mathbf{0 . 5}}}\right)^{2}
$$


where $M$ is the number of moments. We therefore minimize the sum of the squared t-values of the moments. We obtain parameter estimates for a given weighting matrix, then use these parameter estimates to compute a new weighting matrix. We iterate a couple of times this way until the weighting matrix and parameter estimates no longer change. Under the null that the model is correct, the objective function has a $\chi^{2}$ distribution with degrees of freedom equal to the number of moments minus the number of estimated prameters.

The variance covariance matrix of parameter estimates is given by

$$
\frac{1}{S}\left[\left(\frac{\partial \mathbf{m}^{\text {model }}}{\partial \nu}\right)^{\prime} \boldsymbol{\Sigma}^{-1}\left(\frac{\partial \mathbf{m}^{\text {model }}}{\partial \nu}\right)\right]^{-1}
$$

where $S$ is the sample length and the derivatives $\partial \mathbf{m}^{\text {model }} / \partial \nu$ are evaluated at the estimated parameter vector $\hat{\nu}$.

\subsection{Data Moments}

We use 15 data moments for the estimation, which are shown in the first column of Table 2. We include the standard deviations of the excess return and the average portfolio share, as well as the change in the average portfolio share. We also consider the standard deviation of the expected excess return. Since the expected excess return is unobservable, we compute an estimate of it through a regression of the excess return on three lags of the excess return and three lags of portfolio share changes: $e r_{t-i}, z_{t-i}^{A}-z_{t-i-1}^{A}$, for $i=1,2,3$.

We include the autocorrelation of these same variables as well as the autocorrelation of the excess return over 3 quarters, $e r_{t, t+3}$ and the portfolio share change over 3 quarters, $z_{t}^{A}-z_{t-3}^{A}$. Note that the average portfolio share is very persistent, with an autocorrelation of 0.976. Both excess returns and changes in portfolio shares are also positively autocorrelated.

The final set of moments is a set of contemporaneous correlations. We focus on the contemporaneous correlations between endogenous variables and observable shocks. The endogenous variables are the excess return $e r_{t}$ and the change $z_{t}^{A}-z_{t-1}^{A}$ in the average portfolio share. The observable shocks are the wealth/supply shocks $a_{t}^{D}$ and dividend shocks $d_{t}^{D}-d_{t-1}^{D}$. We also consider the correlation between the two endogenous variables. One could include correlations between levels of variables as well, such as $d_{t}^{D}$ and $q_{t}^{D}$ or $z_{t}^{A}$ and $d_{t}^{D}$. But since these levels tend to drift 
during the sample, these correlations vary significantly across simulations and are therefore not very helpful for estimation purposes.

\section{Results}

\subsection{Two Key Findings}

It is useful to start by summarizing the key overall results first.

Result 1 With an unconstrained rate of risk aversion, the model cannot be rejected, no matter the frequency of portfolio changes p. Estimates of risk aversion become extremely large as we raise $p$ above small levels.

Result 2 When constraining risk aversion to reasonable levels, the model is not rejected only when $p<\bar{p}$ with $\bar{p}$ small. In that case most traders are infrequent traders and the frequency of portfolio adjustment is low.

In the remainder of this section we will document these results and explain what drives these findings.

Figure 2 documents both results. The top two charts and bottom left chart show respectively the value of the objective function, estimate of $\tilde{\gamma}$ and estimate of $f$ when we vary $p$ from 0 to 1 , for each value of $p$ re-estimating all the other parameters $\left(\tilde{\gamma}, f, \rho_{1}, \rho_{2}\right.$ and $\left.\sigma_{n}\right)$. Remarkably, the objective function varies very little with $p$. The objective function has a $\chi^{2}$ distribution with 10 degrees of freedom (upper left panel). At the 5 percent significance level we cannot reject the model when the objective function is less than 18.3, which is the case for all values of $p$ from 0 to 1 . No conclusion can therefore be drawn about the frequency of portfolio changes, which is Result 1.

The chart in the upper right of Figure 2 provides insight into what is going on. When $p$ is small, most traders are infrequent traders as estimates of $f$ are small (bottom left chart). As we raise $p$, at some point the estimate of $f$ drops to 0 , but this makes little difference as the infrequent traders become like frequent traders when they change portfolios very frequently. The key point is that the estimate of $\tilde{\gamma}$ rises monotonically as we raise $p$ and reaches the astronomical number of 485 when $p=1$. This is the same case as $f=1$. As we will discuss further below, the data is telling us that the portfolio response to expected returns must be weak. As 
Figure 2: IMPACT OF VARYING $\mathrm{P}^{*}$
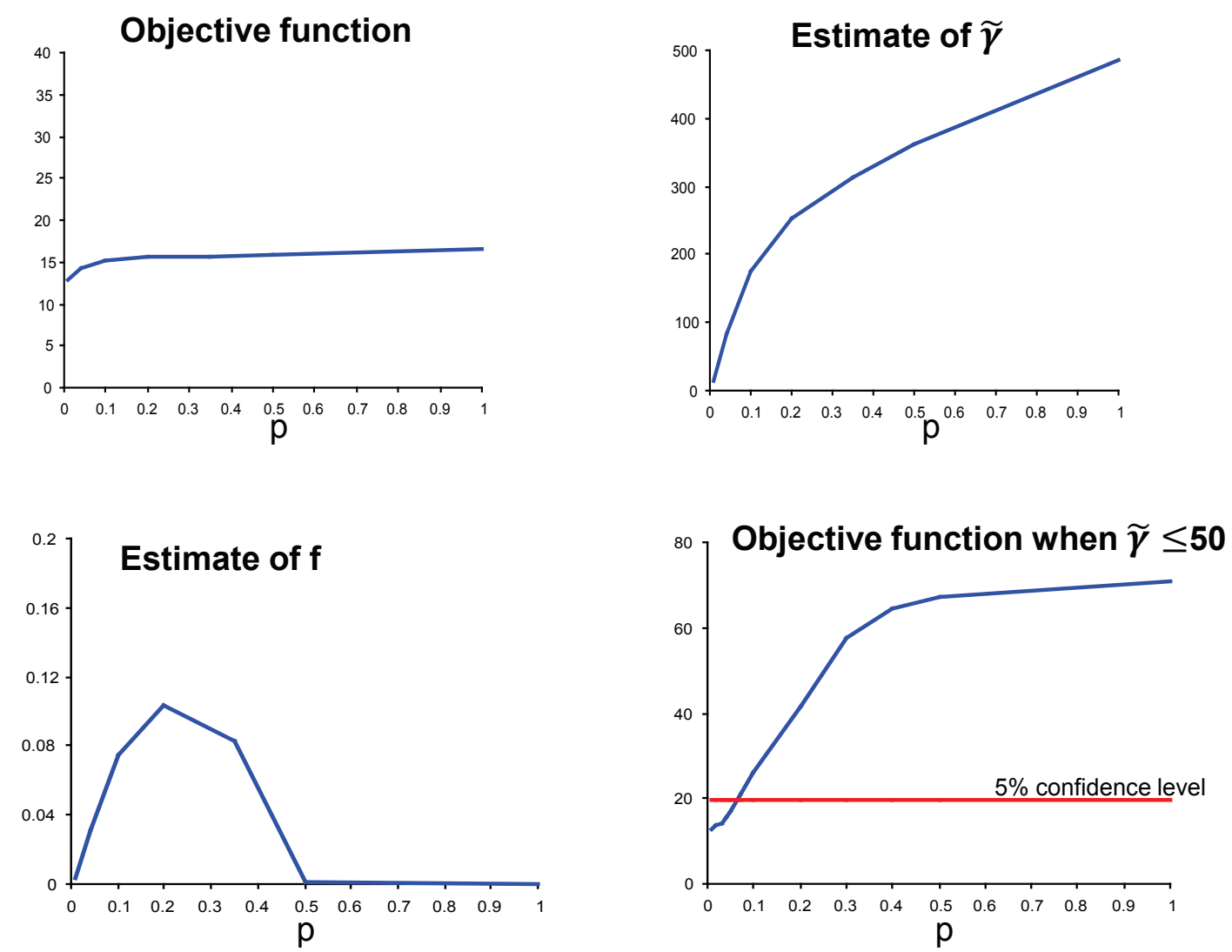

${ }^{*}$ The top two charts and bottom left chart show the objective function, estimate of $\tilde{\gamma}$, and estimate of $f$ when varying $p$ from 0 to 1 while re-estimating all the other parameters. The bottom right chart shows the objective function when varying $p$, while re-estimating the other parameters under the constraint $\tilde{\gamma} \leq 50$. The 5 percent confidence level is the value of the objective function below which we cannot reject the model.

we have seen in Section 3.6, this can happen either through infrequent portfolio adjustment (low $p$ ) or through a high risk aversion $\tilde{\gamma}$.

The results in Figure 2 suggests that the data is not able to distinguish between weakening the portfolio response by raising $\tilde{\gamma}$ and lowering $p$. They are essentially substitutes. As we raise $p$ from 0 to 1 , making portfolios more responsive to expected returns, the estimate of $\tilde{\gamma}$ rises, making portfolios less responsive. This is not to say that the response to shocks is very similar in cases with low $p$ and $\tilde{\gamma}$ as in cases with high $p$ and $\tilde{\gamma}$. We saw in the impulse responses in Figure 1 that the dynamic response to dividend and wealth shocks is remarkably different in the IN 
case (mostly infrequent traders with low $p$ ) to the FRH case (only frequent traders with high risk aversion). The estimation is nonetheless unable to separate the IN case from the FRH case. The reasons for this will be further explored in Section 5.3. But before we do so, we first discuss Result 2.

The bottom right chart of Figure 2 shows the objective function when we restrict $\tilde{\gamma}$ to be no larger than 50. This becomes binding when $p>0.03$, as can be seen from the upper right chart. When $p=0.01$, risk aversion $\tilde{\gamma}$ is estimated to be 13.9 , but then quickly rises as $p$ rises. The bottom right chart shows that restricting $\tilde{\gamma}$ to be no larger than 50 leads to a sharp rise in the objective function the moment this becomes binding. The chart also shows the level of the objective function where we are unable to reject the model at a 5 percent significance level. This will be the case as long as $p<0.065$, with the upper bound representing an expected length between portfolio changes of 15 months. As we increase $p$ further, without raising $\tilde{\gamma}$ further, portfolios become too responsive to expected returns to be consistent with the data. The features of the data that lead to this are discussed below. First though we need to make some comments on the logic of restricting risk aversion.

The adjusted risk-aversion parameter $\tilde{\gamma}$ differs from the curvature $\gamma$ of the utility function, but connects more closely to estimates of risk aversion in the literature based on portfolio data and the price individuals are willing to pay to avoid risky gambles. Most estimates of risk aversion are less than 10, and tend to be closer to 1 than 10. Mehra and Prescott (1985) famously showed that such risk-aversion parameters are insufficient to match the observed equity premium 27 Mehra (2003) finds that risk-aversion just below 50 is needed to match the equity premium. Kocherlakota (2001) finds that a risk-aversion of 18 is sufficient. While such higher rates of risk aversion are inconsistent with a lot of micro studies, Kandel and Stambaugh (1991) argue that these are often based on very large risky bets. For smaller risky bets as a fraction of an investor's wealth, a higher rate of risk aversion of 30 implies more reasonable bets. To accommodate such considerations, we allow for a risk-aversion $\tilde{\gamma}$ up to 50. Clearly though, extreme risk-aversion of 485 that we estimate when there are only frequent traders is well beyond anything that is reasonable.

\footnotetext{
${ }^{27}$ Our model has no implications for the equity premium as we have focused on differences of the equations (33)-36], which allow us to solve the expected equity return of the Home country relative to the Foreign country as opposed the expected excess return of equity over bonds.
} 
As long as we are willing to constrain risk aversion to such "reasonable" levels, the conclusion is that the data implies values of $p$ no larger than 0.065 . This is Result 2.

\subsection{Model Moments}

We will now further explore what features of the data give rise to Result 2 by considering the 15 model moments used to estimate model parameters. In Table 2 we report the model moments for two values of $p$ less than 0.065: $p=0.01$ and $p=$ 0.04. The objective function is a bit lower for $p=0.01$ than $p=0.04$ (respectively 12.8 and 15.5), but we cannot reject the model in either case ${ }^{28} p=0.01$ implies an average length of 8 years between portfolio adjustments, while $p=0.04$ implies a more plausible average period of 2 years between portfolio changes ${ }^{29}$

Table 2 reports both data and model moments, as well as the t-value, which is the difference between the model moment and the data moment divided by the standard deviation of the model moment. For $p=0.01$ the t-value is always less than 2 , so that all model moments are consistent with the data. For $p=0.04$, only two moments have t-values just slightly above 2 . Clearly, the fit of the model is very strong in both cases.

Table 3 reports results when there are only frequent traders $(p=1$ or $f=1)$. Results are reported for three levels of risk aversion: $\tilde{\gamma}=10, \tilde{\gamma}=50$ and $\tilde{\gamma}=485$. The latter is the level of risk aversion we estimate without imposing constraints of $\tilde{\gamma}$. The objective function is respectively $184,70.7$ and 16.5 in these three cases. As discussed above, only for extreme risk aversion are we unable to reject the model with only frequent traders.

Table 3 identifies the moments that lead to the weak performance of the model with frequent traders only for reasonable rates of risk aversion. The standard deviation of the change in the portfolio share, $z_{t}^{A}-z_{t-1}^{A}$ is too high relative to the

\footnotetext{
${ }^{28}$ When we estimate $p$ without any constraint we find implausible values of both $p$ and $\tilde{\gamma}$ very close to 0 , which is why we do not report these. As can be seen from the upper left chart of Figure 2, the objective function is just a little bit higher for extremely low values of $p$.

${ }^{29}$ This is the same frequency of price changes that Bacchetta and van Wincoop (2010) use to explain the forward discount puzzle, though they assume a constant rather than stochastic time interval between portfolio changes for individual agents. They argue that this frequency is reasonable based on both direct evidence of the frequency of portfolio changes and evidence based on portfolio Euler equations, which fit better with 1-3 year horizons.
} 
Table 2: Data and Model Moments with Gradual Portfolio AduustMENT

\begin{tabular}{|c|c|c|c|c|c|}
\hline & & \multicolumn{2}{|c|}{$p=0.01$} & \multicolumn{2}{|c|}{$p=0.04$} \\
\hline & DATA & Model & t-value & Model & t-value \\
\hline \multicolumn{6}{|c|}{ STANDARD DEVIATIONS } \\
\hline$e r_{t}$ & 0.0271 & 0.0263 & 0.65 & 0.0262 & 0.66 \\
\hline$z_{t}^{A}$ & 0.0261 & 0.0254 & 0.09 & 0.0285 & 0.23 \\
\hline$z_{t}^{A}-z_{t-1}^{A}$ & 0.0045 & 0.0046 & 0.17 & 0.0046 & 0.35 \\
\hline$E_{t} e r_{t+1}-$ estimate & 0.0067 & 0.0058 & 0.54 & 0.0062 & 0.31 \\
\hline \multicolumn{6}{|c|}{ AUTOCORRELATIONS } \\
\hline$e r_{t}$ & 0.086 & 0.143 & 0.81 & 0.161 & 1.07 \\
\hline$e r_{t, t+3}$ & 0.191 & 0.092 & 1.05 & 0.091 & 1.07 \\
\hline$z_{t}^{A}$ & 0.976 & 0.978 & 0.18 & 0.982 & 0.43 \\
\hline$z_{t}^{A}-z_{t-1}^{A}$ & 0.155 & 0.161 & 0.09 & 0.182 & 0.39 \\
\hline$z_{t}^{A}-z_{t-3}^{A}$ & 0.059 & 0.110 & 0.53 & 0.112 & 0.56 \\
\hline$E_{t} e r_{t+1}-$ estimate & 0.231 & 0.289 & 0.23 & 0.308 & 0.34 \\
\hline \multicolumn{6}{|c|}{ CONTEMPORANEOUS CORRELATIONS } \\
\hline $\operatorname{corr}\left(a_{t}^{D}, e r_{t}\right)$ & 0.401 & 0.295 & 1.89 & 0.274 & 2.21 \\
\hline $\operatorname{corr}\left(a_{t}^{D}, z_{t}^{A}-z_{t-1}^{A}\right)$ & 0.024 & -0.094 & 1.90 & -0.116 & 2.24 \\
\hline $\operatorname{corr}\left(d_{t}^{D}-d_{t-1}^{D}, e r_{t}\right)$ & 0.177 & 0.146 & 0.50 & 0.163 & 0.21 \\
\hline $\operatorname{corr}\left(d_{t}^{D}-d_{t-1}^{D}, z_{t}^{A}-z_{t-1}^{A}\right)$ & 0.248 & 0.146 & 1.60 & 0.163 & 1.34 \\
\hline $\operatorname{corr}\left(e r_{t}, z_{t}^{A}-z_{t-1}^{A}\right)$ & 0.922 & 0.922 & 0.02 & 0.922 & 0.03 \\
\hline Objective & & & 12.8 & & 15.5 \\
\hline Parameter Estimates & & & s.e. & & s.e. \\
\hline$\tilde{\gamma}$ & & 13.9 & 1.73 & 50 & \\
\hline$\rho_{1}$ & & 1.6180 & 0.071 & 1.6606 & 0.017 \\
\hline$\rho_{2}$ & & -0.6182 & 0.072 & -0.6611 & 0.017 \\
\hline$\sigma_{n}$ & & 0.0029 & 0.0004 & 0.0029 & 0.0001 \\
\hline$f$ & & 0.0039 & 0.0014 & 0.0146 & 0.0006 \\
\hline
\end{tabular}

*The Table shows results for 2 cases: (i) $p=0.01$, (ii) $p=0.04$. The estimated parameters of $\tilde{\gamma} \leq 50$, the noise process $\left(\rho_{1}, \rho_{2}\right.$, and $\left.\sigma_{n}\right)$ and $f$, and standard errors, are at the bottom of the table. The table reports the average model moments over 1000 simulations (under Model) and the t-value of each moment. The latter is the difference between the average model moment and data moment, divided by the standard deviation of the model moment based on the 1000 simulations. The objective function is shown right below the moments, which corresponds to the sum of the squared t-values of the moments. 
Table 3: Data And Model Moments when $p=1$

\begin{tabular}{|c|c|c|c|c|c|c|c|}
\hline & & \multicolumn{2}{|c|}{$\tilde{\gamma}=10$} & \multicolumn{2}{|c|}{$\tilde{\gamma}=50$} & \multicolumn{2}{|c|}{$\tilde{\gamma}=485$} \\
\hline & DATA & Model & $\mathrm{t}$-value & Model & $\mathrm{t}$-value & Model & t-value \\
\hline \multicolumn{8}{|c|}{ STANDARD DEVIATIONS } \\
\hline$e r_{t}$ & 0.0271 & 0.0313 & 2.68 & 0.0286 & 1.01 & 0.0263 & 0.62 \\
\hline$z_{t}^{A}$ & 0.0261 & 0.0275 & 0.21 & 0.0235 & 0.47 & 0.0241 & 0.33 \\
\hline$z_{t}^{A}-z_{t-1}^{A}$ & 0.0045 & 0.0059 & 4.80 & 0.0053 & 2.92 & 0.0046 & 0.21 \\
\hline$E_{t} e r_{t+1}-$ estimate & 0.0067 & 0.0057 & 0.51 & 0.0055 & 0.64 & 0.0053 & 0.79 \\
\hline \multicolumn{8}{|c|}{ AUTOCORRELATIONS } \\
\hline$e r_{t}$ & 0.086 & 0.056 & 0.38 & 0.069 & 0.22 & 0.085 & 0.01 \\
\hline$e r_{t, t+3}$ & 0.191 & 0.123 & 0.56 & 0.148 & 0.34 & 0.177 & 0.12 \\
\hline$z_{t}^{A}$ & 0.976 & 0.973 & 0.24 & 0.970 & 0.39 & 0.979 & 0.24 \\
\hline$z_{t}^{A}-z_{t-1}^{A}$ & 0.155 & 0.054 & 1.33 & 0.068 & 1.11 & 0.096 & 0.75 \\
\hline$z_{t}^{A}-z_{t-3}^{A}$ & 0.059 & 0.119 & 0.49 & 0.147 & 0.69 & 0.197 & 1.16 \\
\hline$E_{t} e r_{t+1}-$ estimate & 0.231 & 0.185 & 0.15 & 0.229 & 0.01 & 0.294 & 0.20 \\
\hline \multicolumn{8}{|c|}{ CONTEMPORANEOUS CORRELATIONS } \\
\hline $\operatorname{corr}\left(a_{t}^{D}, e r_{t}\right)$ & 0.401 & 0.035 & 6.01 & 0.112 & 4.83 & 0.297 & 1.86 \\
\hline $\operatorname{corr}\left(a_{t}^{D}, z_{t}^{A}-z_{t-1}^{A}\right)$ & 0.024 & -0.277 & 5.15 & -0.237 & 4.35 & -0.093 & 1.85 \\
\hline $\operatorname{corr}\left(d_{t}^{D}-d_{t-1}^{D}, e r_{t}\right)$ & 0.177 & 0.514 & 6.95 & 0.357 & 3.19 & 0.104 & 1.16 \\
\hline $\operatorname{corr}\left(d_{t}^{D}-d_{t-1}^{D}, z_{t}^{A}-z_{t-1}^{A}\right)$ & 0.248 & 0.491 & 4.84 & 0.345 & 1.68 & 0.103 & 2.25 \\
\hline $\operatorname{corr}\left(e r_{t}, z_{t}^{A}-z_{t-1}^{A}\right)$ & 0.922 & 0.949 & 4.08 & 0.937 & 1.81 & 0.921 & 0.09 \\
\hline Objective & & & 184.0 & & 70.7 & & 16.5 \\
\hline Parameter Estimates & & & s.e. & & s.e. & & s.e. \\
\hline$\tilde{\gamma}$ & & 10 & & 50 & & 484.6 & 13.9 \\
\hline$\rho_{1}$ & & 1.9741 & 0.002 & 1.9707 & 0.001 & 1.9409 & 0.004 \\
\hline$\rho_{2}$ & & -0.9790 & 0.002 & -0.9759 & 0.001 & -0.9448 & 0.004 \\
\hline$\sigma_{n}$ & & 0.0140 & 0.0001 & 0.00377 & 0.0002 & 0.00086 & 0.00002 \\
\hline
\end{tabular}

*The Table assumes $p=1$ and reports results for 3 cases: (i) $\tilde{\gamma}=10$, (ii) $\tilde{\gamma}=50$ and (iii) $\tilde{\gamma}$ estimated without restriction. The estimated parameters of the noise process $\left(\rho_{1}, \rho_{2}\right.$ and $\left.\sigma_{n}\right)$ and $\tilde{\gamma}$, and standard errors, are at the bottom of the table. The table reports the average model moments over 1000 simulations (under Model) and the t-value of each moment. The latter is the difference between the average model moment and data moment, divided by the standard deviation of the model moment based on the 1000 simulations. The objective function is shown right below the moments, which corresponds to the sum of the squared t-values of the moments. 
data, while the contemporaneous correlations are even more inconsistent with the data. To understand this, it is useful to go back to the impulse responses in Figure 1. The case of infrequent traders (IN) corresponds to the parameterization with $p=0.01$ in Table 2. The two cases with only frequent traders, FRH and FRL, correspond to respectively the case of $\tilde{\gamma}=485$ and $\tilde{\gamma}=10$ in Table 3 .

In the FRL case, the immediate portfolio response to both dividend and wealth shocks is very large. Although there are also financial shocks, which we will discuss below, this contributes to the finding that $z_{t}^{A}-z_{t-1}^{A}$ is too volatile. Next consider the contemporaneous correlations. The first four of them relate to the contemporaneous correlation between dividend and wealth changes on the one hand and the excess return and change in average portfolio share on the other hand. This relates closely to the contemporaneous response of $q^{D}$ and $z^{A}$ to dividend and wealth shocks reported in Figure 1 .

First consider wealth shocks $a_{t}^{D}$. A positive relative Home wealth shock implies an increased relative demand for the Home assets and therefore a rise in $q_{t}^{D}$ and $e r_{t}$. This leads to a positive correlation between $a_{t}^{D}$ and $e r_{t}$, which is 0.4 in the data. But in the FRL case there is a sharp drop in the average portfolio share $z^{A}$ as the increase in $q^{D}$ lowers the expected excess return. This significantly dampens the rise in $q^{D}$, leading to a correlation between the excess return and the wealth shock that is much lower than in the data. The sharp drop in $z^{A}$ also leads to a strongly counterfactual negative correlation between the change in $z^{A}$ and the wealth shock. The model performs better when the portfolio response is much weaker, either due to infrequent traders with low $p$ or a very large $\tilde{\gamma}$. This is also illustrated in Figure 1, where we see that in the IN and FRH cases $q^{D}$ rises much more and $z^{A}$ drops much less in response to the shock.

The next two contemporaneous correlations are between the change in the $\log$ dividend $d_{t}^{D}-d_{t-1}^{D}$ and respectively $z_{t}^{A}-z_{t-1}^{A}$ and $e r_{t}$. As we see in the impulse responses in Figure 1, in the FRL case where portfolios are very sensitive to expected returns both the average portfolio share and the relative price are very responsive to changes in dividends. This is because higher Home dividends, which are persistent, imply a higher expected return on Home equity that leads to a large portfolio shift to Home equity. The correlation between the change in dividends and both the excess return and portfolio share change are higher in the model than in the data. This problem is again resolved by weakening the portfolio response to expected returns, either through a low $p$ or high $\tilde{\gamma}$, as can be seen in Figure 1 . 
So far we have not discussed the financial shocks. Figure 3 reports the impulse response to financial shocks (increase in $n_{t}$ ) for the same three parameter combinations as for dividend and wealth shocks in Figure 1 $p=0.01$ (IN), $f=1, \tilde{\gamma}=10$ (FRL) and $f=1, \tilde{\gamma}=485$ (FRH). A key difference with the dividend and wealth shocks is that the financial shocks cannot be directly measured. The parameters of the $\operatorname{AR}(2)$ process for $n_{t}$, reported in Tables 2 and 3 , are such that the model moments fit the data as well as possible. In all three cases the financial shock is therefore different, while wealth and dividend shocks are always the same.

Figure 3: Impulse Response, Financial Shocks*
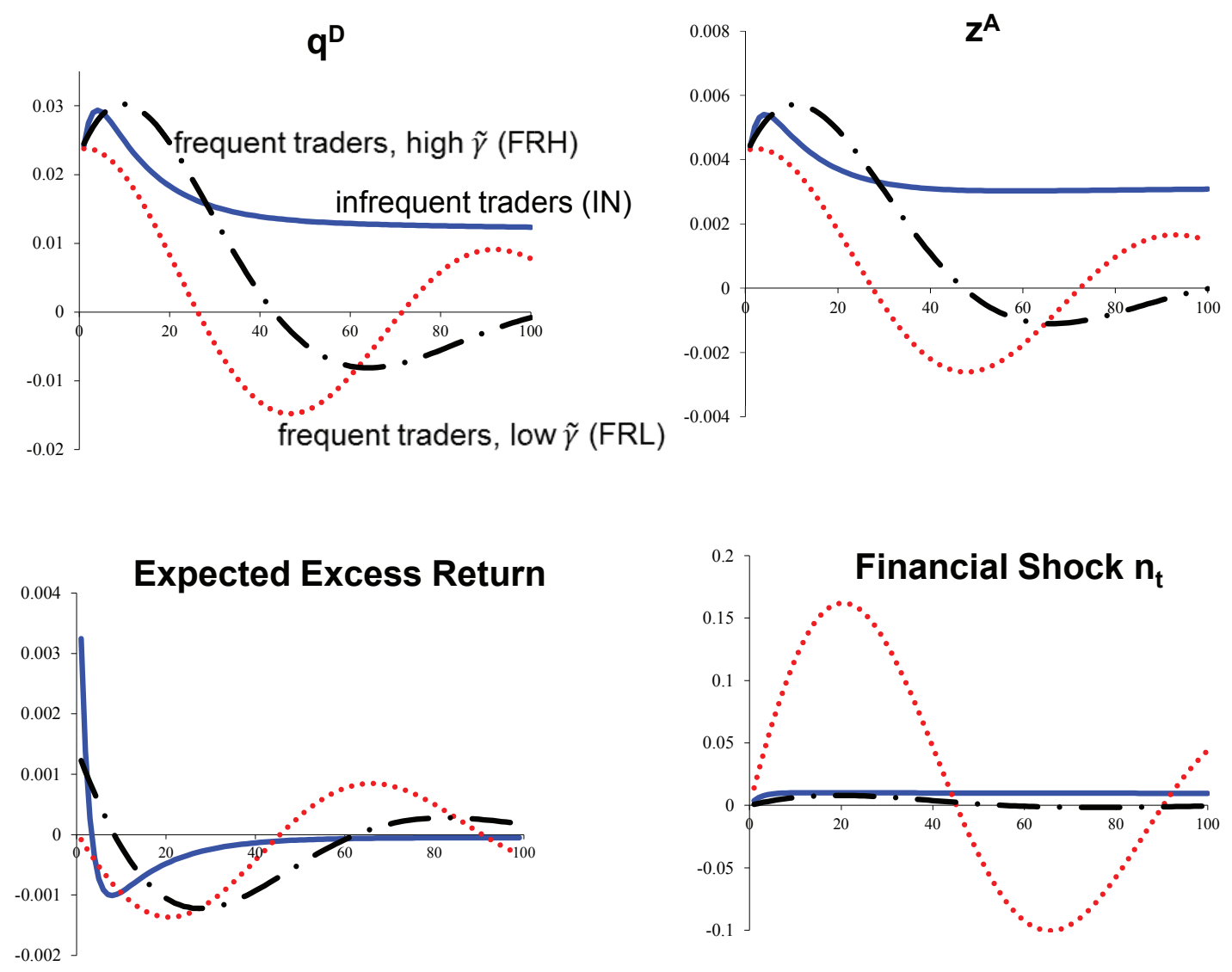

*Infrequent traders (IN): $p=0.01, f=0.004, \tilde{\gamma}=13.9$; frequent traders, low $\tilde{\gamma}(\mathrm{FRL}): f=1, \tilde{\gamma}=$ 10; frequent traders, high $\tilde{\gamma}(\mathrm{FRH}): f=1, \tilde{\gamma}=485$. Others parameters as in Tables 1-3.

The bottom right chart in Figure 3 shows $n_{t}$ over time in response to a one standard deviation financial shock. The magnitude of the financial shock in the 
FRL case is massive compared to the IN and FRH cases. The reason for this is that financial shocks have very little effect when portfolios are very sensitive to expected returns. A small change in the asset price that leads to a small change in the expected excess return can generate a very large portfolio shift that clears markets in response to the exogenous portfolio shift $n_{t}$. As a result the financial shock needs to be made extremely big in order to make it matter.

In the FRL case the increase in $n_{t}$ peaks at 0.16 after just a one standard deviation financial innovation in a particular month. This translates into a change in the average allocation to Home equity from 0.5 to 0.66 with a one standard deviation shock and 0.82 with a two standard deviation shock. Such massive shocks are highly implausible. The same is the case as well when $\tilde{\gamma}=50$. This further reinforces that the model with frequent traders and plausible risk aversion is not a good description of the data. For reasonable levels of risk aversion the model is only consistent with the data when agents change their portfolios infrequently.

\subsection{Infrequent Trading versus Frequent Trading with Ex- treme Risk Aversion}

A remaining question is why it is so hard to distinguish the IN and FRH cases. Even if we set aside the extreme risk aversion of 485 in the FRH case, should we not be able to separate the IN and FRH cases based on features of the data? If we look at the impulse response to the observed dividend and wealth shocks in Figure 1, we see that the instantaneous response of $q^{D}$ and $z^{A}$ is quite similar in the IN and FRH cases. It is for this reason that the contemporaneous correlations in the FRH case (last two columns of Table 3) and IN case ( $p=0.01$ in Table 2) are similar, both consistent with the data. But we also see in Figure 1 that the subsequent dynamics is quite different.

This difference in dynamics subsequent to the shock can be captured by various correlations that measure predictability. These are correlations between variables at time $t$ and excess returns or portfolio share changes over the next 1, 3 and 12 months. We report the results for these correlations in Table 4 . The variables at time $t$ include the change in the relative dividend $d_{t}^{D}-d_{t-1}^{D}$, the level $d_{t}^{D}$ of the relative dividend, the wealth shock $a_{t}^{D}$, the portfolio share change $z_{t}^{A}-z_{t-1}^{A}$ and the excess return $e r_{t}$. Results are reported for both the IN case $(p=0.01)$ and the FRH case $(f=1, \tilde{\gamma}=485)$. 
Table 4: Correlations Capturing Predictability

\begin{tabular}{|c|c|c|c|c|c|}
\hline & & \multicolumn{2}{|c|}{$\overline{p=0.01}$} & \multicolumn{2}{|c|}{$p=1, \tilde{\gamma}=485$} \\
\hline & DATA & Model & t-value & Model & t-value \\
\hline \multicolumn{6}{|c|}{ ONE-MONTH FORWARD CORRELATIONS } \\
\hline $\operatorname{corr}\left(d_{t}^{D}-d_{t-1}^{D}, z_{t+1}^{A}-z_{t}^{A}\right)$ & -0.059 & 0.027 & 1.29 & 0.000 & 0.88 \\
\hline $\operatorname{corr}\left(d_{t}^{D}-d_{t-1}^{D}, e r_{t+1}\right)$ & -0.036 & 0.030 & 0.99 & 0.003 & 0.59 \\
\hline $\operatorname{corr}\left(d_{t}^{D}, z_{t+1}^{A}-z_{t}^{A}\right)$ & -0.027 & 0.030 & 0.84 & -0.006 & 0.26 \\
\hline $\operatorname{corr}\left(d_{t}^{D}, e r_{t+1}\right)$ & -0.001 & 0.044 & 0.72 & 0.022 & 0.29 \\
\hline $\operatorname{corr}\left(a_{t}^{D}, z_{t+1}^{A}-z_{t}^{A}\right)$ & -0.105 & -0.019 & 1.34 & -0.001 & 1.61 \\
\hline $\operatorname{corr}\left(a_{t}^{D}, e r_{t+1}\right)$ & -0.088 & -0.025 & 0.98 & -0.008 & 1.24 \\
\hline $\operatorname{corr}\left(z_{t}^{A}-z_{t-1}^{A}, e r_{t+1}\right)$ & 0.127 & 0.163 & 0.50 & 0.093 & 0.43 \\
\hline $\operatorname{corr}\left(e r_{t}, z_{t+1}^{A}-z_{t}^{A}\right)$ & 0.100 & 0.162 & 0.87 & 0.099 & 0.01 \\
\hline \multicolumn{6}{|c|}{ THREE-MONTH FORWARD CORRELATIONS } \\
\hline $\operatorname{corr}\left(d_{t}^{D}-d_{t-1}^{D}, z_{t+3}^{A}-z_{t}^{A}\right)$ & -0.046 & 0.036 & 1.32 & -0.002 & 0.72 \\
\hline $\operatorname{corr}\left(d_{t}^{D}-d_{t-1}^{D}, e r_{t, t+3}\right)$ & -0.056 & 0.040 & 1.55 & 0.003 & 0.96 \\
\hline $\operatorname{corr}\left(d_{t}^{D}, z_{t+3}^{A}-z_{t}^{A}\right)$ & -0.032 & 0.036 & 0.67 & -0.009 & 0.18 \\
\hline $\operatorname{corr}\left(d_{t}^{D}, e r_{t, t+3}\right)$ & 0.011 & 0.058 & 0.49 & 0.034 & 0.19 \\
\hline $\operatorname{corr}\left(a_{t}^{D}, z_{t+3}^{A}-z_{t}^{A}\right)$ & 0.002 & -0.025 & 0.39 & 0.001 & 0.01 \\
\hline $\operatorname{corr}\left(a_{t}^{D}, e r_{t, t+3}\right)$ & 0.050 & -0.035 & 1.27 & -0.010 & 0.89 \\
\hline $\operatorname{corr}\left(z_{t}^{A}-z_{t-1}^{A}, e r_{t, t+3}\right)$ & 0.120 & 0.141 & 0.30 & 0.132 & 0.14 \\
\hline $\operatorname{corr}\left(e r_{t}, z_{t+3}^{A}-z_{t}^{A}\right)$ & 0.097 & 0.142 & 0.64 & 0.144 & 0.56 \\
\hline \multicolumn{6}{|c|}{ 12-MONTH FORWARD CORRELATIONS } \\
\hline $\operatorname{corr}\left(d_{t}^{D}-d_{t-1}^{D}, z_{t+12}^{A}-z_{t}^{A}\right)$ & -0.076 & 0.050 & 2.03 & -0.000 & 1.21 \\
\hline $\operatorname{corr}\left(d_{t}^{D}-d_{t-1}^{D}, e r_{t, t+12}\right)$ & -0.023 & 0.058 & 1.32 & 0.008 & 0.51 \\
\hline $\operatorname{corr}\left(d_{t}^{D}, z_{t+12}^{A}-z_{t}^{A}\right)$ & 0.010 & 0.012 & 0.02 & -0.012 & 0.11 \\
\hline $\operatorname{corr}\left(d_{t}^{D}, e r_{t, t+12}\right)$ & 0.053 & 0.045 & 0.05 & 0.048 & 0.03 \\
\hline $\operatorname{corr}\left(a_{t}^{D}, z_{t+12}^{A}-z_{t}^{A}\right)$ & 0.005 & -0.029 & 0.49 & 0.003 & 0.03 \\
\hline $\operatorname{corr}\left(a_{t}^{D}, e r_{t, t+12}\right)$ & 0.103 & -0.048 & 2.20 & -0.016 & 1.73 \\
\hline $\operatorname{corr}\left(z_{t}^{A}-z_{t-1}^{A}, e r_{t, t+12}\right)$ & 0.031 & 0.010 & 0.30 & 0.115 & 0.96 \\
\hline $\operatorname{corr}\left(e r_{t}, z_{t+12}^{A}-z_{t}^{A}\right)$ & 0.049 & 0.023 & 0.37 & 0.147 & 1.08 \\
\hline
\end{tabular}

*The Table shows results for one-month, 3-month and 12-month predictive correlations in two cases: (i) $p=0.01$ (Table 2), (ii) $p=1$ and $\tilde{\gamma}=485$ (Table 3). T-values are computed analogously to Tables 2 and 3 . 
The key takeaway from Table 4 is that for both the IN and FRH case the model is consistent with the data. Almost all t-values are less than 2. Correlations capturing the predictability of excess returns and portfolio shares therefore provide little guidance. The moments vary significantly across model simulations. For example, the correlation between the relative dividend $d_{t}^{D}$ and the subsequent excess return $e r_{t+1}$ is 0.044 in the infrequent trading model, but the 95 percent confidence interval in the model is $[-0.08,0.17]$. This is consistent with the data moment of -0.001 , but if the model is correct the data moment could also have been a substantial positive number.

There are two reasons for this result. The first is the large role of the unobserved financial shocks. A comparison of the scales in Figures 1 and 3 shows that financial shocks have an immediate impact on $q^{D}$ and $z^{A}$ that is 3-10 times larger as for dividend and wealth shocks. The dominant role of the unobserved financial shocks makes it harder to observe predictability of excess returns and portfolio changes. The role of these shocks can be determined by removing them in the model. We find that financial shocks increase the standard deviation of the model moments across simulations. Even more important, they significantly reduce the size of the correlations in Table 4, sometimes by a factor 3 or 4 .

The second factor that plays a role in making predictability harder to identify is associated with the magnitude of the dividends shocks. This relates to the point above as it would be easier to identify predictability the larger the dividend shocks relative to financial shocks. One can draw a comparison to the foreign exchange market, where Bacchetta and van Wincoop (2010) find that a model with gradual portfolio adjustment is consistent with excess return predictability in the data. In the foreign exchange market exchange rate fluctuations are also dominated by financial shocks and the standard deviation of quarterly excess returns is similar to the quarterly excess returns in our data for equity. ${ }^{30}$ However, the volatility of the income component of the excess return is much higher in the foreign exchange market. The interest differential is about three times as volatile as the income component of the excess return in the equity market, $\delta d_{t}^{D}$.

With a higher standard deviation of dividends $\sigma_{d}$, the correlations in the data in Table 4 would likely have been higher and it might have been easier to separate the IN and FRH cases. As an experiment we triple $\sigma_{d}$ to make the income component

\footnotetext{
${ }^{30}$ See also Itskhoki and Mukhin (2017) for the importance of financial shocks for exchange rate determination.
} 
equally volatile as in the foreign exchange market. We find that the correlations between $d_{t}^{D}$ and the subsequent excess return and portfolio share change rise significantly in the IN case. Both correlations also increase relative to the FRH case, where correlations with subsequent portfolio share changes actually become more negative 31

\section{Conclusion}

Even though there is a growing body of evidence consistent with gradual portfolio adjustment, modern open economy macro models assume the exact opposite: the continuous adjustment of international portfolio allocation by all investors. This paper introduces gradual portfolio adjustment to an open economy model of the equity market and confronts it with data on international portfolio shares and equity prices.

Apart from a focus on open economy aspects, we have contributed along two dimensions to the literature on gradual portfolio adjustment. First, we have developed a theory of infrequent portfolio adjustment where the timing of portfolio changes is stochastic, following a Poisson distribution instead of taking place at predictable intervals of constant length. This leads to a smoother response of endogenous variables to shocks than in models where the length of time between portfolio decisions is fixed. Second, we have used both asset price data and portfolio data to evaluate the implications of the model empirically. This contrasts with work to date that has focused mostly on data features involving asset prices only. It is natural to consider evidence on portfolios since after all this is a theory of gradual portfolio adjustment.

Our findings can be summarized with two key results. Conditional on a reasonable rate of risk aversion, we find that the data is consistent with infrequent portfolio decisions, with an average frequency of at most once in 15 months. We find that the model where all agents adjust portfolios continuously, when combined with plausible rates of risk aversion, leads to an excessive response of portfolios to expected returns that generates inconsistencies with the data. At the same time we are unable to distinguish the model with infrequent portfolio decisions

\footnotetext{
${ }^{31}$ Another factor that may play a role in predictability is that there are larger measurement errors associated with $d_{t}^{D}$ than with the interest differential. We have also used relative dividends instead of relative earnings for $d_{t}^{D}$, but this does not improve predictability.
} 
from one where all agents choose an optimal portfolio at all times and the rate of risk aversion is extremely large, well above what is plausible. The latter also leads to a weak portfolio response to expected returns. While these imply different dynamics with different predictability of excess returns and portfolios shares, the relatively large role of unobserved financial shocks makes it hard to separate them empirically.

Looking to future work, several directions should be considered. First, on the modeling front we have made the assumption that agents hold portfolio shares constant when they do not make a new portfolio decision. This implies complete rebalancing. We need to consider the implications under the alternative of not rebalancing at all, as well as partial rebalancing. In addition, instead of assuming a constant consumption/wealth ratio it would be attractive to model the joint consumption and portfolio decision, even though this will generate additional computational challenges. Second, on the empirical front we need to consider extending the approach to other markets where both asset returns and portfolio shares are available. While we have discussed a two-country model for the global equity market (US versus rest of world), one could consider a multi-country model, using data on portfolio shares allocated to individual foreign countries. The Bertaut and Tryon (2007) and Bertaut and Judson (2014) data are also available for the bond market, which is another natural application. The framework can be applied to closed economy setting as well, for example considering the portfolio allocation between stocks and bonds within the United States. 


\section{Appendix}

\section{Appendix A. Data Description}

Using MSCI data notation, the precise data definition for excess returns is:

$$
\begin{aligned}
e r_{t}= & \ln \left(\text { msci_us_TR }_{t} / \text { msci_us_TR }_{t-1}\right) \\
& -\ln \left(\text { msci_acwi_exus_TR }_{t} / \text { msci_acwi_exus_TR }_{t-1}\right)
\end{aligned}
$$

where msci_us_TR is "MSCI US Total Return Index" and msci_acwi_exus_TR is "MSCI ACWI ex US Total Return Index" (ACWI stands for "All Country World").

$d_{t}^{D}$ is computed as relative earnings and earnings are derived by dividing the price index (PI) by the price earnings ratio (PER):

$d_{t}^{D}=\ln ($ msci_us_PI/msci_us_PER)-ln (msci_acwi_us_PI/msci_acwi_us_PER)

For portfolio shares, we use:

$$
\begin{aligned}
z_{H t} & =\frac{\text { US external claims on ROW }}{\text { US market capitalization-US external liabilities + US external claims on ROW }} \\
z_{F t} & =\frac{\text { ROW external claims on US }}{\text { ROW market capitalization - US external claims + ROW external claims on US }}
\end{aligned}
$$

US market capitalization: msci_us_MV; ROW market capitalization: msci_acwi_exus_MV. US external claims on ROW : us_stk_est_pos derived bertaut_tryon_claims_thru2011.csv and bertaut_judson_positions_claims_2015.csv.

ROW external claims on US: ftot_stk_est_pos derived from ticdata.liabilities.ftot.txt and bertaut_judson_positions_liabs_2015.csv. Both are for all countries, item 69995. We use all countries for ROW rather than using bilateral data for the 44 countries in MSCI data. Bilateral country data may be biased because it does not always capture the true destination or source country (e.g., portfolios with financial centers).

Appendix B. Hedge Terms Optimal Portfolio

For a variable $x$, define

$$
\tilde{x}_{t, t+i}=\sum_{j=1}^{i} \theta^{1-j} x_{t+j}
$$


As shown in the Technical Appendix, where we derive the optimal portfolio of infrequent traders, the hedge term for Home infrequent investors is

$$
h_{H t}^{i n}=\frac{1-\beta \theta}{\beta \theta} \frac{N_{H t}}{D}
$$

where

$$
\begin{aligned}
& N_{H t}=-\sum_{s=1}^{\infty} \sum_{i=1}^{s-1}(\beta \theta)^{s} p_{i} \gamma \theta^{s-i} \operatorname{cov}\left(\tilde{e r}_{t, t+i}, \tilde{r}_{t+i, t+s}^{p H}\right) \\
& -\sum_{s=1}^{\infty} \sum_{i=1}^{s-1}(\beta \theta)^{s} p_{i} \gamma \frac{1-\theta}{\theta} \theta^{s} \operatorname{cov}\left(\tilde{e r}_{t, t+i}, \tilde{g}_{H, t, t+s}\right) \\
& +\sum_{s=1}^{\infty} \sum_{i=1}^{s-1}(\beta \theta)^{s} p_{i} \frac{1-\theta}{\theta} \sum_{j=1}^{i} \operatorname{cov}\left(\tilde{g}_{H, t, t+j-1}, e r_{t+j}\right) \\
& +\sum_{s=1}^{\infty} \sum_{i=1}^{s-1}(\beta \theta)^{s} p_{i} \operatorname{cov}\left(\tilde{e r}_{t, t+i}, \hat{r}_{t+i, t+s}^{p H}\right) \\
& -\sum_{s=1}^{\infty}(\beta \theta)^{s}\left(1-\sum_{m=1}^{s-1} p_{m}\right) \gamma \frac{1-\theta}{\theta} \theta^{s} \operatorname{cov}\left(\tilde{e r}{ }_{t, t+s}, \tilde{g}_{H, t, t+s}\right) \\
& +\sum_{s=1}^{\infty}(\beta \theta)^{s}\left(1-\sum_{m=1}^{s-1} p_{m}\right) \frac{1-\theta}{\theta} \sum_{j=1}^{s} \operatorname{cov}\left(\tilde{g}_{H, t, t+j-1}, e r_{t+j}\right) \\
& +\sum_{s=1}^{\infty} \sum_{i=1}^{s-1} \sum_{j=1}^{i}(\beta \theta)^{s} p_{i} \theta^{1-j} \tau_{H t} \\
& +\sum_{s=1}^{\infty} \sum_{j=1}^{s}(\beta \theta)^{s} \theta^{1-j}\left(1-\sum_{m=1}^{s-1} p_{m}\right)_{H t}
\end{aligned}
$$

The terms involve a hedge against future portfolio returns and non-asset income, as well as fee $\tau_{H t}$ of investing abroad.

For Foreign investors the hedge term is the same, with $N_{H t}$ replaced by $N_{F t}$. Superscripts and subscripts $H$ are placed with $F$ and $\tau_{H t}$ is replaced with $-\tau_{F t}$. The average hedge term $h_{t}^{A, i n}=\left(h_{H t}^{i n}+h_{F t}^{i n}\right) / 2$ is much simpler as all terms other than those involving the fees $\tau_{H t}$ and $\tau_{F t}$ drop out. The reason for this is that when we add up the Home and Foreign hedge terms, the covariances in all cases can be written as a covariance between the excess return and the average of variables across countries. This covariance is zero as the Home and Foreign returns by symmetry have the same covariance with variables that are an average across 
countries. As shown in the Technical Appendix, we have

$$
h_{t}^{A, i n}=\frac{0.5}{D(1-\beta(1-p))} \tau_{t}^{D}
$$

Analogously, for frequent traders

$$
h_{t}^{A, f}=\frac{0.5}{\tilde{\gamma} v a r_{t}\left(e r_{t+1}\right)} \tau_{t}^{D}
$$

Appendix C. Estimate of $\theta$

It is useful to repeat (47) here:

$$
\tilde{w}_{t}^{D}=\theta \tilde{w}_{t-1}^{D}+\theta(2 \bar{z}-1) e r_{t}+a_{t}^{D}
$$

We find that $a_{t}^{D}$ is essentially iid for any reasonable value of $\theta$. One could then set $\theta$ from $(64)$ by using that $\operatorname{cov}\left(a_{t}^{D}, w_{t-1}^{D}\right)=0$. But in finite samples this covariance is not zero. We therefore proceed as follows. We first write $e r_{t}=\eta_{1} a_{t}^{D}+e_{t}^{1}$, where $e_{t}^{1}$ is by construction orthogonal to $a_{t}^{D}$. We then write $e_{t}^{1}=\eta_{2} w_{t-1}^{D}+e_{t}^{2}$, where $e_{t}^{2}$ is by construction orthogonal to $w_{t-1}^{D}$. This implies

$$
\tilde{w}_{t}^{D}=\xi_{1} \tilde{w}_{t-1}^{D}+e_{t}
$$

where $\xi_{1}=\theta+\theta(2 \bar{z}-1) \eta_{2}$ and $e_{t}=\theta(2 \bar{z}-1) e_{t}^{2}+\left(1+\theta(2 \bar{z}-1) \eta_{1}\right) a_{t}^{D}$. By construction $e_{t}$ is orthogonal to $w_{t-1}^{D}$. For a range of values of $\theta$ we then simulate (65) 1000 times, using the standard deviations of $e_{t}^{2}$ and $a_{t}^{D}$, and compute the average of $\operatorname{cov}\left(a_{t}^{D}, w_{t-1}^{D}\right)$. We set $\theta$ such that this average covariance corresponds to the actual covariance. This gives $\theta=0.988$, which we round to 0.99 . 


\section{References}

[1] Abel, Andrew B., Janice C. Eberly and Stavros Panageas (2007), "Optimal Inattention in the Stock Market," American Economic Review Papers and Proceedings, May 2007, 244-249.

[2] Abel, Andrew B. , Janice C. Eberly, and Stavros Panageas (2013), "Optimal Inattention to the Stock Market with Information Costs and Transactions Costs," Econometrica 81, No. 4, 1455-1481.

[3] Albuquerque, Rui, Gregory H. Bauer and Martin Schneider (2009), "Global Private Information in International Equity Markets," Journal of Financial Economics 94(1), 18-46.

[4] Albuquerque, Rui, Gregory H. Bauer and Martin Schneider (2007), "International Equity Flows and Returns: A Quantitative Equilibrium Approach," Review of Economic Studies 74(1), 1-30.

[5] Allen, Franklin and Douglas Gale (1994), "Limited Market Participation and Volatility of Asset Prices," American Economic Review 84, 933-955.

[6] Altonji, Joseph G. and Lewis M. Segal (1996), "Small-Sample Bias in GMM Estimation of Covariance Structures," Journal of Business and Economic Statistics 14 (3), 353-366.

[7] Ameriks, John and Stephen Zeldes (2004), "How do Household Portfolio Shares vary with Age," working paper.

[8] Bacchetta, Philippe and Eric van Wincoop (2010), "Infrequent Portfolio Decisions: A Solution to the Forward Discount Puzzle," American Economic Review 100, 837-869.

[9] Bertaut, Carol C. and Ruth Judson (2014), "Estimating U.S. Cross-Border Securities Positions: New Data and New Methods," Board of Governors of the Federal Reserve System (U.S.), International Finance Discussion Paper 1113.

[10] Bertaut, Carol C. and Ralph W. Tryon (2007), "Monthly Estimates of U.S. Cross-Border Securities Positions, " Board of Governors of the Federal Reserve System (U.S.), International Finance Discussion Paper 910. 
[11] Bilias, Yannis, Dimitris Georgarakos and Michael Haliassos (2010), "Portfolio Inertia and Stock Market Fluctuations" Journal of Money, Credit and Banking 42: 715-742.

[12] Blanchard, Olivier, Irineu de Carvalho Filho, and Gustavo Adler (2015), "Can Sterilized Foreign Exchange Intervention Stem Exchange Rate Pressures from the Global Financial Cycle?,"IMF Working Paper 2015-159.

[13] Bogousslavsky, Vincent (2016), "Infrequent Rebalancing, Return Autocorrelation, and Seasonality," Journal of Finance LXXI (6), 2967-3006.

[14] Bohn, Henning and Linda L. Tesar (1996), "U.S. Equity Investment in Foreign Markets: Portfolio Rebalancing or Return Chasing?" American Economic Review 86, 77-81.

[15] Brennan, Michael J. and H. Henry Cao (1997), "International Portfolio Investment Flows," The Journal of Finance 52, 1851-1880.

[16] Brunnermeier, Markus and Stefan Nagel (2008), "Do Wealth Fluctuations Generate Time-Varying Risk-Aversion? Micro-Evidence on Individuals' Asset Allocation," American Economic Review 98, 713-736.

[17] Bruno, Valentina and Hyun Song Shin (2015), "Capital flows and the risktaking channel of monetary policy," Journal of Monetary Economics 71, 119132.

[18] Calderon, Cesar, Norman Loayza and Luis Serven (2003), "Do capital flows respond to risk and return? ," Policy, Research working paper series, no. WPS 3059. Washington, DC: World Bank.

[19] Calvo, Guillermo, Leonardo Leiderman, and Carmen Reinhart (1996), "Inflows of Capital to Developing Countries in the 1990s," Journal of Economic Perspectives 10(2),123-139.

[20] Campbell, John Y. (1993), "Intertemporal Asset Pricing without Consumption Data," American Economic Review 83(3): 487-512.

[21] Viceira, Luis M., and John Y. Campbell (2002), "Strategic Asset Allocation: Portfolio Choice for Long-Term Investors," Oxford University Press. 
[22] Chien, Yili, Harold Cole, and Hanno Lustig (2012), "Is the Volatility of the Market Price of Risk Due to Intermittent Portfolio Rebalancing," American Economic Review 102, 2859-2896.

[23] Coeurdacier, Nicolas (2009), "Do Trade Costs in Goods Markets lead to Home Bias in Equities?," Journal of International Economics 77, 86-100.

[24] Coeurdacier, Nicolas, Stephane Guibaud and Harjoat Bhamra (2014), "A Dynamic Equilibrium of Imperfectly Integrated Financial Markets," Journal of Economic Theory 54, 490-542.

[25] Curcuru, Stephanie E., Tomas Dvorak, Francis E. Warnock (2008), "CrossBorder Return Differentials," Quarterly Journal of Economics 123(4), 14951530.

[26] Curcuru, Stephanie E., Tomas Dvorak, Francis E. Warnock (2010), "Decomposing the U.S. External Returns Differential," Journal of International Economics 80(1), 22-32.

[27] Curcuru, Stephanie E., Charles P. Thomas, Francis E. Warnock and Jon Wongswan (2011), "US International Equity Investment and Past and Prospective Returns," American Economic Review 101, 3440-3455.

[28] Devereux, Michael B. and Alan Sutherland (2010), "Country Portfolio Dynamics," Journal of Economic Dynamics and Control, 34, 1325-1342.

[29] Devereux, Michael B. and Alan Sutherland (2007), "Monetary Policy and Portfolio Choice in an Open Economy Macro Model," Journal of the European Economic Association 5, 491-499.

[30] Didier, Tatiana and Alexandre Lowenkron (2012), "The Current Account as a Dynamic Portfolio Choice Problem," Journal of The Japanese and International Economies 26, 518-541.

[31] Duffie, Darrell (2010), "Asset Price Dynamics with Slow-Moving Capital," Journal of Finance LXV, 1237-1267.

[32] Evans, Martin D.D. and Hnatkovska, Viktoria V. (2014), "International Capital Flows, Returns and World Financial Integration," Journal of International Economics 92(1), 14-33. 
[33] Froot, Kenneth A., Paul G.J. O'Connell, Mark S. Seasholes (2001), "The Portfolio Flows of International Investors," Journal of Financial Economics 59, 151-193.

[34] Gabaix, Xavier and David Laibson (2002), "The 6D Bias and the Equity Premium Puzzle,"in Ben Bernanke and Kenneth Rogoff, eds, NBER Macroeconomics Annual, 16, 257-312.

[35] Gabaix, Xavier and Matteo Maggiori (2015), "International Liquidity and Exchange Rate Dynamics," Quarterly Journal of Economics 130(3), 13691420.

[36] Gali, Jordi (2008), Monetary Policy, Inflation, and the Business Cycle: An Introduction to the New Keynesian Framework and Its Applications, Princeton University Press.

[37] Gourio, Francois, Michael Siemer and Adrien Verdelhan (2014), "Uncertainty and International Capital Flows," mimeo.

[38] Greenwood, Robin, Samuel G. Hanson, and Gordon Y. Liao (2015), "Price Dynamics in Partially Segmented Markets," mimeo.

[39] Hendershott, Terrence, Sunny X. Li, Albert J. Mankfeld, Mark S. Seasholes (2013), "Asset Price Dynamics with Limited Attention," mimeo.

[40] Hnatkovska, Viktoria V. (2010), "Home Bias and High Turnover: Dynamic Portfolio Choice with Incomplete Markets," Journal of International Economics 80(1), 113-128.

[41] Hong, Harrison and Jeremy C. Stein (1999), "A United Theory of Underreaction, Momentum Trading and Overreaction in Asset Markets," Journal of Finance 54(6), 2143-2184.

[42] Itskhoki, Oleg and Dmitry Mukhin (2017), "Exchange Rate Disconnect in General Equilibrium," working paper, Princeton University.

[43] Jeanne, Olivier and Andrew K. Rose (2002), "Noise Trading and Exchange Rate Regimes," Quarterly Journal of Economics 117, 537-569. 
[44] Kandel, Shmuel and Robert Stambaugh (1990), "Asset Returns and Intertemporal Preferences," Journal of Monetary Economics 1991, 27(1), 39-71.

[45] Kocherlakota, Narayana R. (1996), "The Equity Premium: It's Still a Puzzle," Journal of Economic Literature 34, 42-71.

[46] Kraay, Aart and Jaume Ventura (2000), "Current Accounts in Debtor Countries and Creditor Countries," Quarterly Journal of Economics 115 (4): 11371166.

[47] Krussel, Per and Anthony A. Smith (1997), "Income and Wealth Heterogeneity, Portfolio Choice, and Equilibrium Asset Returns," Macroeconomic Dynamics $1(2), 387-422$.

[48] Lynch, Anthony W. (1996), "Decision Frequency and Synchronization Across Agents: Implications for Aggregate Consumption and Equity Return," The Journal of Finance 51(4), 1479-1497.

[49] Mankiw, N. Gregory and Ricardo Reis (2002), "Sticky Information versus Sticky Prices: A Proposal to Replace the New Keynesian Phillips Curve," Quarterly Journal of Economics 117, 1295-1328

[50] Martin, Philippe and Helene Rey (2004), "Financial Super-Markets: Size Matters for Asset Trade," Journal of International Economics 64, 335-361.

[51] McCafferty, Stephen and Robert Driskill (1980), "Problems of Existence and Uniqueness in Nonlinear Rational Expectations Models," Econometrica 48, $1313-1317$

[52] Mehra, Rajnish (2003), "The Equity Premium: Why is it a Puzzle?," Financial Analyst Journal, January/February, 54-69.

[53] Mehra, Rajnish and Edward C. Prescott (1985), "The Equity Premium: A Puzzle," Journal of Monetary Economics 15(2), 145-61.

[54] Mitchell, Olivia S., Gary R. Mottola, Stephen P. Utkus and Takeshi Yamaguchi (2006), "The Inattentive Participant: Portfolio Trading Behavior in 401(k) plans," working paper. 
[55] Pagano, Marco (1989), "Endogenous Market Thinness and Stock Price Volatility," Review of Economic Studies 56, 269-288.

[56] Tille, Cédric and Eric van Wincoop (2010), "International Capital Flows," Journal of International Economics 80(2), 157-175.

[57] Tille, Cédric and Eric van Wincoop (2014), "International Capital Flows under Dispersed Private Information," Journal of International Economics 93(1), 31-49.

[58] Vayanos, Dimitri and Paul Woolley (2012), "An Institutional Theory of Momentum and Reversal," Review of Financial Studies 6, 1087-1145.

[59] Warnock, Francis E. and Veronica Cacdac Warnock (2009), "International Capital Flows and U.S. Interest Rates," Journal of International Money and Finance 28, 903-919. 